\title{
Chemical-specific adjustment factors (inter-species toxicokinetics) to establish the ADI for steviol glycosides
}

Ashley Roberts ${ }^{a, \star}$, Sidd Purkayastha ${ }^{b}$, Sachin Bhusaric, George Pugh, Jr. ${ }^{c}$, Barry Lynch ${ }^{a}$, Rebecca Rogerson ${ }^{\mathrm{a}}$, Christine Crincolid, Alex Eapen ${ }^{\mathrm{d}}$, Nicole Cuellar-Kingston ${ }^{\mathrm{d}}$, Hua Kern ${ }^{\mathrm{e}}$, Matthew Coffee ${ }^{f}$, Michael Carakostas ${ }^{g}$, Andrew Renwick ${ }^{h}$

${ }^{a}$ Intertek Scientific \& Regulatory Consultancy, 2233 Argentia Rd., Suite 201, Mississauga, ON, Canada L5N 2X7

b PureCircle Limited, 915 Harger Road, Suite 250, Oak Brook, IL, USA 60523

c The Coca-Cola Company, One Coca-Cola Plaza; Atlanta, GA, USA 30126

d Cargill, Incorporated, 15407 McGinty Rd W., Wayzata, MN, USA 55391

e Biofortis Clinical Research, 211 East Lake Street, Addison, IL, USA 60101

${ }^{\dagger}$ WIL Research, 1407 George Road, Ashland, OH, USA 44805-8946

${ }^{9}$ ToxStrategies, Inc., 2 Reeve Crt \#200, St. Helena Island, SC, USA, 29920

${ }^{\mathrm{h}}$ Faculty of Medicine, Highfield, University of Southampton, Southampton SO17 1BJ, UK

$\begin{array}{ll}\text { Word Count: } & \\ \text { Abstract: } & 195 \\ \text { Text: } & 7660 \\ \text { References: } & 1451\end{array}$

Abbreviations: $\lambda_{z}$, terminal elimination constant; $A D I$, acceptable daily intake; $A_{U} C_{0 \text {-last, }}$ area under the curve from time zero until the last sampling time point; $A E$, adverse events; $A U C$, area under the plasma concentration-time curve; $A \cup C_{-0.75-i n f, ~}$ AUC from time zero to infinity; $A \cup C_{\text {last }}, A \cup C$ to the last quantifiable observation; BLQ, below the limit of quantification; $B M I$, body mass index; bw, body weight; $\mathrm{C}_{\max }$, concentration maximum; CSAF, chemical-specific adjustment factor; EE, efficacy evaluable population; EKG, electrocardiogram; HBsAg, hepatitis B surface antigen; IQR, interquartile range; IRB, Institutional Review Board; JECFA, Joint FAO/WHO Expert Committee on Food Additives; LC-MS/MS, liquid chromatography-tandem mass spectrometry; LLOQ, lower limit of quantification, LOQ, limit of quantification; NOAEL, noobserved-adverse-effect level; $\mathrm{PP}$, per protocol population; $\mathrm{SD}$, standard deviation; $\mathrm{T}_{1 / 2}$, half-life; $\mathrm{T}_{\max }$, time to maximum concentration; $\mathrm{WHO}$, World Health Organization

* Corresponding author: Tel: +1-905-542-2900

E-mail address: ashley.roberts@intertek.com 


\section{Abstract}

The acceptable daily intake (ADI) of commercially available steviol glycosides is currently 4 $\mathrm{mg} / \mathrm{kg}$ body weight (bw)/day, based on application of a 100-fold uncertainty factor to a noobserved-adverse-effect-level value from a chronic rat study. Within the 100 -fold uncertainty factor is a 10-fold uncertainty factor to account for inter-species differences in toxicokinetics (4fold) and toxicodynamics (2.5-fold). Single dose pharmacokinetics of stevioside were studied in rats (40 and $1,000 \mathrm{mg} / \mathrm{kg} \mathrm{bw}$ ) and in male human subjects ( $40 \mathrm{mg} / \mathrm{kg} \mathrm{bw}$ ) to generate a chemical-specific, inter-species toxicokinetic adjustment factor. $T_{\max }$ values for steviol were at $\sim 8$ and $\sim 20$ hours after administration in rats and humans, respectively. Peak concentrations of steviol were similar in rats and humans, while steviol glucuronide concentrations were significantly higher in humans. Glucuronidation in rats was not saturated over the dose range 40-1,000 $\mathrm{mg} / \mathrm{kg}$ bw. The $\mathrm{AUC}_{0 \text {-last }}$ for steviol was approximately 2.8 -fold greater in humans compared to rats. Chemical-specific adjustment factors for extrapolating toxicokinetics from rat to human of 1 and 2.8 were established based on $\mathrm{C}_{\max }$ and $\mathrm{AUC}_{0 \text {-last }}$ data respectively. Because these factors are lower than the default value of 4.0, a higher ADI for steviol glycosides of between 6 to $16 \mathrm{mg} / \mathrm{kg}$ bw/d is justified.

Keywords: steviol glycosides; pharmacokinetics; rats; humans; ADI 


\section{Introduction}

Steviol glycosides (steviol conjugated with glucose, xylose, rhamnose, and/or other sugar moieties) are natural constituents of the Stevia rebaudiana (Bertoni) plant. At least 40 different steviol glycosides have been identified in the leaves of S. rebaudiana (Ohta et al., 2010; Chaturvedula and Prakash, 2011a,b; Chaturvedula et al., 2011a-c; Ceunen and Geuns, 2013). Each of these steviol glycosides has its own unique taste profile and sweetness intensity, which can be up to 350 times sweeter than sugar, but all share a similar molecular structure where different sugar moieties are attached to the aglycone steviol (an ent-kaurene-type diterpene). The generic structure of the steviol glycosides is presented in Figure 1.

The metabolic fate of steviol glycosides has been well documented in the literature. Steviol glycosides pass undigested through the upper gastrointestinal tract to the colon where they are hydrolyzed to steviol by sequential removal of one sugar moiety at a time, prior to absorption of steviol (Wingard et al., 1980; Hutapea et al., 1997; Gardana et al., 2003; Koyama et al., 2003a,b; Geuns et al., 2003, 2007; Renwick and Tarka, 2008; Purkayastha et al., 2015). In rats (Roberts and Renwick, 2008), pigs (Geuns et al., 2003) and humans (Geuns et al., 2007; Wheeler et al., 2008) exposures to the parent steviol glycosides are negligible following oral exposure. Once absorbed from the gastrointestinal tract, steviol undergoes conjugation with glucuronic acid in the liver to form steviol glucuronide. In rats, free and conjugated steviol are excreted primarily in the feces via the bile (generally within 48 hours), with smaller amounts appearing in the urine (less than 3\%) (Wingard et al., 1980; Roberts and Renwick, 2008). In contrast, elimination of administered steviol glycosides in humans, is primarily in the urine as steviol glucuronide with very small amounts of the unchanged glycoside or steviol (Kraemer and Maurer, 1994; Simonetti et al., 2004; Geuns et al., 2006, 2007; Wheeler et al., 2008). Recent studies using human fecal homogenates have demonstrated that regardless of the type of sugar 
moieties or linkages present on the steviol backbone, these are hydrolyzed to the common metabolite steviol (Purkayastha et al., 2014, 2015, 2016).

The Joint FAO/WHO Expert Committee on Food Additives (JECFA) reviewed the safety of steviol glycosides at four separate meetings (51st, 63rd, 68th and 69th) in 1998, 2004, 2007 and 2008 (JECFA, 2000, 2006, 2007, 2009). JECFA has established specifications and an acceptable daily intake (ADI) for stevia extract as a high potency sweetener. The safety of steviol glycosides was established on the basis of a common metabolic pathway for steviol glycosides between rats and humans, thus allowing for the extrapolation of toxicology and other safety data on the major steviol glycosides, namely rebaudioside $A$ and stevioside, as well as the metabolite steviol, to other structurally related steviol glycosides that have not been specifically assessed in safety studies. This approach was employed recently in European Food Safety Authority (EFSA, 2015) to include rubusoside and to allow any combination of 11 steviol glycosides on the basis of a common metabolic fate so long as steviol glycosides comprised $\geq 95 \%$ of the mixture. The current ADI of 0-4 mg steviol equivalents $/ \mathrm{kg}$ body weight (bw)/day was based on a no-observed-adverse-effect level (NOAEL) of $400 \mathrm{mg} / \mathrm{kg} \mathrm{bw/d}$ identified from a chronic study of stevioside in rats (Toyoda et al., 1997). The ADI is thought to be particularly conservative given the existence of other subchronic toxicity studies on steviol glycosides in which no adverse effects were noted at much higher doses than the NOAEL identified in the chronic rat study (Curry and Roberts, 2008; Nikiforov and Eapen, 2008).

Although steviol glycosides share a common metabolic fate in both rats and humans (Wingard et al., 1980; Hutapea et al., 1997; Gardana et al., 2003; Koyama et al., 2003a; Geuns et al., 2007; Roberts and Renwick, 2008; Wheeler et al., 2008; Nikiforov et al., 2013; Purkayastha et al., 2014, 2015, 2016), some differences in pharmacokinetics have been noted. As evaluated by JECFA at their sixty-ninth meeting (JECFA, 2009), studies comparing the pharmacokinetics of steviol and steviol glucuronide following oral administration of steviol glycosides 
demonstrated substantial differences in the concentration of circulating plasma steviol and steviol glucuronide between rats and humans (Roberts and Renwick, 2008; Wheeler et al., 2008). Specifically, 4 and $8 \mathrm{~h}$ after a single gavage administration of radiolabeled stevioside $(4.2 \mathrm{mg} / \mathrm{kg} \mathrm{bw})$ to male rats free steviol was detected in the plasma at concentrations of approximately 20 and $18 \mathrm{ng} / \mathrm{mL}$ respectively (Roberts and Renwick, 2008). In female rats, concentrations of approximately 40,46 and $80 \mathrm{ng} / \mathrm{mL}$ of steviol were detected at 2, 4 and $8 \mathrm{~h}$ post-dose, respectively. Steviol glucuronide was detected at $8 \mathrm{~h}$ post-dose in both male and female rats, with approximately 12 and $22 \mathrm{ng}$ steviol equivalents $/ \mathrm{mL}$ quantified, respectively. At all other time points, both steviol and steviol glucuronide were below the lower limits of quantification (8.9 and $10.0 \mathrm{ng}$ steviol equivalents $/ \mathrm{mL}$, respectively). Conversely, in a study in humans given $4.2 \mathrm{mg}$ stevioside/ $\mathrm{kg}$ bw, free steviol $(121 \mathrm{ng} / \mathrm{mL})$ was detected only in the plasma of one subject at one time point (6 $\mathrm{h}$ after administration) (Wheeler et al., 2008); in contrast, steviol glucuronide reached detectable levels in the plasma as soon as $2 \mathrm{~h}$ post-dose. By $5 \mathrm{~h}$ post-dose, detectable levels of plasma steviol glucuronide were identified in seven of eight subjects, with plasma concentrations peaking at $8 \mathrm{~h}$ post administration $(1,886 \mathrm{ng} / \mathrm{mL}$ as the geometric mean). Based on the differences in the glucuronidation of steviol between humans and rats observed in these studies, it therefore appeared that the exposure to free steviol in humans could be much lower than in comparison to rats and as such the current 100 fold uncertainty factor used to calculate the current ADI, based on steviol (free) equivalents may be overly conservative.

While the results of the studies of Roberts and Renwick (2008) and Wheeler et al. (2008) point to possibly lower systemic exposures to free steviol, or at least lower free steviol relative to steviol glucuronide, in humans compared to the rat (the species from which most toxicology data available), direct comparison of these studies is complicated by the use of different analytical methodologies and resulting different lower limits of quantification, and differences in 
sample processing. In addition, quantification of the potential magnitude of differences in the toxicokinetics of steviol/steviol glucuronide between rats and humans was not possible because detectable levels of steviol were found in only one human subject at one time point.

As a result, further focused research into the potential pharmacokinetic differences between rats and humans in regards to the generation of plasma steviol/steviol glucuronide following oral administration of steviol glycosides was necessary in order to derive an inter-species, toxicokinetic, chemical-specific adjustment factor (CSAF) as defined by the World Health Organization (WHO) (WHO, 2005). A CSAF value less than the standard default value of 100 will result in an increase in the ADI which is independent of the NOAEL without requiring the conduct of an additional long-term toxicity study.

Based on the limited data available it was hypothesized that, the toxicokinetic differences between rats and humans are minimal and, providing that suitable data were available, could be accounted for by an inter-species toxicokinetic CSAF in the derivation of an ADI for steviol glycosides. The objective of this research was therefore to define the potential interspecies differences in the plasma pharmacokinetics of steviol, the product of steviol glycoside hydrolysis. To achieve this, comparative studies were conducted in rats and humans.

\section{Materials and methods}

\subsection{Studies in rats}

\subsubsection{Test material}

The test material, stevioside (supplied by The Coca-Cola Company, Atlanta, GA; batch number: GLG-STV95-2014-030, $\geq 95 \%$ pure) is a white to off-white hygroscopic powder. The test material was stored at room temperature $\left(18-24^{\circ} \mathrm{C}\right)$ and desiccated upon receipt from the 
supplier. Homogeneity, concentration, and stability of the dosing solutions were confirmed prior to dosing.

\subsubsection{Study design}

The study was designed as a single-dose oral gavage study to determine the pharmacokinetics of steviol and steviol glucuronide in rats. A single dose gavage study was considered appropriate since there was no prior evidence to suggest that there would be a change in steviol glycoside pharmacokinetics following continuous treatment (steady state) due to changes in bioavailability, clearance or enzyme induction. The study was conducted at WIL Research (Ashland, $\mathrm{OH}$ ), in compliance with the United States Food and Drug Administration Good Laboratory Practice Standards (21 CFR Part 58, 1987) (U.S. FDA, 2015), in accordance with all applicable sections of the Final Rules of the Animal Welfare Regulations found in Title 9 of the Code of Federal Regulations, and according to the protocol and WIL Research Standard Operating Procedures. All animals were maintained in accordance with the Guide for the Care and Use of Laboratory Animals (National Research Council, 2011).

\subsubsection{Animals and housing conditions}

Male and female Sprague-Dawley [Crl:CD (SD)] rats were obtained from Charles River Laboratories, Inc. and acclimatized for 7 days. The animals were 7-9 weeks of age, weighing $175-350 \mathrm{~g}$ at the time of dosing. Animals were assessed for health conditions upon receipt and were housed individually in clean, solid-bottom cages with bedding material (Bed-O-Cobs ${ }^{\circledR}$ ). The animals were provided food (PMI Nutrition International, LLC Certified Rodent LabDiet ${ }^{\circledR}$ 5002) and reverse osmosis-purified municipal water ad libitum. During the study, animals were housed in a facility designed to maintain appropriate environmental conditions $\left(19-25^{\circ} \mathrm{C}, 30\right.$ $70 \%$ relative humidity, 12-h light/dark cycle, minimum 10 fresh air exchanges/h). 


\subsubsection{Test material administration}

At the end of the acclimation period, animals judged to be in good health and suitable for the study were randomly assigned to two groups of 72 male and 72 female rats. Stevioside, dissolved in vehicle (deionized water for Group 1 and polyethylene glycol [PEG400] for Group 2), was administered via a single oral gavage dose $(10 \mathrm{~mL} / \mathrm{kg} \mathrm{bw})$ to the two groups of male and female rats at dose levels of 40 and $1,000 \mathrm{mg} / \mathrm{kg}$ bw, respectively. These doses equate to 16 and $40 \mathrm{mg} / \mathrm{kg} \mathrm{bw} / \mathrm{d}$ as steviol equivalents. Individual doses were based on the body weight measured on the day of dosing. Animals were fasted overnight prior to dosing through $2 \mathrm{~h}$ postdosing. For direct comparison purposes, the dose of $40 \mathrm{mg} / \mathrm{kg}$ bw was similar to the dose level that was used for the human pharmacokinetic study.

\subsubsection{Clinical observations and necropsy}

Animals were evaluated and observed for clinical signs at the time of dosing and approximately $2 \mathrm{~h}$ post-dosing. Mortality/moribundity was observed twice daily for the duration of the study. Body weights were measured on the day of receipt, on the day of randomization, and prior to dosing.

\subsubsection{Blood sample collection and analysis}

On the day of dosing, blood samples were collected from 6 animals/sex/time point/group prior to dosing and at $0.5,1,2,4,6,8,12,24,36,48$, and $72 \mathrm{~h}$ following dose administration. Animals were euthanized by $\mathrm{CO}_{2}$ inhalation and blood samples (maximum volume, targeting $5 \mathrm{~mL} /$ time point) were collected from the inferior vena cava into chilled tubes containing lithium heparin. Blood samples were kept chilled until centrifuged under refrigerated conditions (approximately $4^{\circ} \mathrm{C}$ ), and the resultant plasma was stored frozen (approximately $-70^{\circ} \mathrm{C}$ ) until transferred to the WIL Research Bioanalytical Chemistry Department (Ashland, $\mathrm{OH}$ ) for analysis. Plasma 
samples were analyzed for steviol and steviol glucuronide concentration using a validated liquid chromatography-tandem mass spectrometry (LC-MS/MS) method. The lower limit of quantification (LLOQ) for steviol and steviol glucuronide was 20 and $4 \mathrm{ng} / \mathrm{mL}$, respectively. The results of these analyses were used for pharmacokinetic evaluation. All toxicokinetic parameters were calculated from the mean plasma concentration data and included the maximum measured concentration of the analyte in plasma $\left(\mathrm{C}_{\max }\right)$, the sampling time at which $\mathrm{C}_{\max }$ was reached $\left(\mathrm{T}_{\max }\right)$, area under the plasma concentration vs. time curve (AUC), dose proportionality, and the terminal half-life $\left(T_{1 / 2}\right)$.

\subsubsection{Data processing}

Pharmacokinetic parameters were calculated using non-compartmental sparse sampling methods as implemented in the Phoenix ${ }^{\circledR}$ WinNonlin $^{\circledR}$ version 6.3 comprehensive toxicokinetic/pharmacokinetic analysis software program (Pharsight Corporation; Mountain View, CA). Values below the lower limit of quantitation (BLQ) were assigned a value of zero for the toxicokinetic and mean (SD) plasma concentration calculations. When all the values at a time point were BLQ, the mean is reported as BLQ and SD is reported as not applicable. All data related to plasma concentrations from all animals were included in the analysis. Nominal doses and times were used for all calculations. Graphical presentations were performed using Prism $^{\circledR}$ for Windows, version 5.04 (GraphPad, Inc.; La Jolla, CA).

\subsection{Humans}

\subsubsection{Study design}

The study was an open-label single-dose design study evaluating the pharmacokinetics of steviol and steviol glucuronide in healthy subjects. The study design included a screening visit (Visit 1, day -21 to -7 ), four test visits during which blood samples were collected for subsequent 
pharmacokinetic analyses (Visits 2, 3, 4 and 5; days 0, 1, 2 and 3), and a follow-up visit at which time final safety assessments were performed (Visit 6; days 5-10). The study was conducted at Biofortis Clinical Research (Addison, IL) in accordance with Good Clinical Practice Guidelines and consistent with the principles in the Declaration of Helsinki. An Institutional Review Board (IRB), IntegReview IRB (Austin, Texas), reviewed and approved the protocol prior to study commencement and subject recruitment. Signed informed consent was obtained from each subject prior to any study-related procedures, and all subjects were informed of their right to withdraw from the study at any time.

\subsubsection{Subjects and inclusion/exclusion criteria}

The study included ten generally healthy male subjects, between the ages of 20 and 45 , with a body mass index (BMI) in the range of $18.50-29.99 \mathrm{~kg} / \mathrm{m}^{2}$. Subjects were considered eligible that had a score of 7-10 on the Vein Access Scale at Visit 1, had no health conditions preventing them from fulfilling the study requirements as judged by the Clinical Investigator, were willing to refrain from consuming all prescription and over-the-counter medication/supplements, caffeine, and alcohol for $12 \mathrm{~h}$ prior to Visit 2 (study initiation) and throughout the study, were non-smokers and did not use any products containing nicotine and tobacco for the previous 6 months with no plans to change smoking habits during the study period, and were willing to maintain habitual diet, physical activity patterns and body weight throughout the study period.

Subjects were excluded if they had abnormal laboratory test results of clinical significance prior to Visit 2, tested positive for urine drug screen and/or breathe alcohol test at Visit 1 and/or 2, had a positive test for hepatitis B surface antigen $(\mathrm{HBsAg})$, hepatitis $\mathrm{C}$, or human immunodeficiency virus at Visit 1 , had lost $\geq 400 \mathrm{~mL}$ of blood (e.g., due to blood donation) within 3 months prior to Visit 2, and had a presence or history of clinically important endocrine, 
cardiovascular, pulmonary, hepatic, renal, hematologic, immunologic, dermatologic, neurologic, psychiatric (including psychosis, major depression or bipolar disorder) or biliary disorders. The study also excluded subjects who had a history or presence of a gastrointestinal disorder that, in the judgment of the Clinical Investigator, could disrupt normal digestion and absorption, had extreme dietary habits (e.g., following Atkins diet, very high protein or vegetarian diet), had uncontrolled hypertension (systolic blood pressure $\geq 140 \mathrm{~mm} \mathrm{Hg}$ or diastolic blood pressure $\geq 90$ $\mathrm{mm} \mathrm{Hg}$ ), had a history or presence of cancer within the past 2 years prior to the study initiation (except for non-melanoma skin cancer), reported weight loss or gain of greater than $4.5 \mathrm{~kg}$ in the previous 3 months of Visit 1, had a known allergy/sensitivity to the study product, or a history of perceived sensitivity to high intensity sweeteners or other food additives. Subjects were also excluded if they used any prescription medicine during the 28 days prior to Visit 2, or used any over-the-counter medicine, including herbal remedies and dietary supplements during the 14 days prior to Visit 2, used reduced/no calorie food and/or beverage products (e.g., diet soda) that may have contained "stevia" products or extracts within 28 days of Visit 2, had exposure to an investigational product in other clinical trials of a prescription medication or new chemical entity within the 3 months prior to Visit 1, had a recent history (within 12 months of Visit 1) or strong potential for alcohol or substance abuse. In addition, subjects having a condition that the Clinical Investigator believed would interfere with his ability to provide informed consent, comply with the study protocol (e.g., confound the interpretation of the study results), or put the subject at undue risk, were also excluded from the study.

\subsubsection{Study product and dosing procedure}

The study product, stevioside (supplied by The Coca-Cola Company, Atlanta, GA; batch number: GLG-STV95-2014-030, 295\% pure, white to off-white hygroscopic powder), was administered at $40 \mathrm{mg} / \mathrm{kg}$ bw, providing $16 \mathrm{mg} / \mathrm{kg}$ bw steviol equivalents. The amount of stevioside administered to each subject to achieve a dosage of $40 \mathrm{mg} / \mathrm{kg}$ bw was determined 
based upon the subjects' body weight. Stevioside was mixed with $50 \mathrm{~mL}$ of deionized water in a dispensing cup and entirely consumed within $5 \mathrm{~min}$. Two additional $50 \mathrm{~mL}$ servings of water were used to rinse the dispensing cup and immediately consumed. Subjects then consumed an additional $200 \mathrm{~mL}$ of water. Stevioside was administered after an overnight fast (10-14 h), and a standard breakfast meal was provided at $0.5 \mathrm{~h}$ ( $\pm 5 \mathrm{~min})$ after dosing. Following the oral administration of stevioside and during the $12 \mathrm{~h}$ the subjects were in the clinic, standard meals were provided as follows: lunch immediately following the $4 \mathrm{~h}$ ( $\pm 5 \mathrm{~min}$ ) post-dosing blood collection time, snack at $9 \mathrm{~h}( \pm 5 \mathrm{~min})$, and dinner at $11 \mathrm{~h} \mathrm{(} \pm 5 \mathrm{~min})$ after dosing. Subjects were instructed to consume all meals in their entirety within $15 \mathrm{~min}$. Water was allowed ad libitum from $0.5 \mathrm{~h}$ post dosing. Subjects were not allowed additional foods aside from the standard meals for the first $24 \mathrm{~h}$.

Additionally, subjects were asked to complete $24 \mathrm{~h}$ diet records for time periods $24-48 \mathrm{~h}$ and 48 $72 \mathrm{~h}$ after dosing to assess the compliance in avoiding caffeine, alcohol and low-/no calorie foods/beverages containing non-nutritive sweeteners, including stevia-based products. All subjects were instructed to avoid low- and no calorie foods/beverages containing non-nutritive sweeteners including stevia-based products for 28 days prior to study commencement and during the blood sampling period. In addition, subjects were instructed to fast for $10-14 \mathrm{~h}$, and to avoid exercise $(24 \mathrm{~h})$, alcohol and caffeine $(12 \mathrm{~h})$ prior to all clinic site visits. Compliance with the study product was recorded in the subject's source document. Non-compliance was witnessed by study staff and defined as not consuming the study product in its entirety at Visit 2 (day 0).

\subsubsection{Study assessments}

At Visit 1, subjects were evaluated for medical history, inclusion and exclusion criteria, medication use, height, body weight, BMI, vital signs (resting blood pressure and heart rate), 
and use of drugs of abuse (amphetamines, cocaine, methamphetamine, cannabis, barbiturates, methadone, benzodiazepines, opiates, phencyclidines, methylenedioxymethamphetamine, oxycodone, propoxyphene, and tri-cyclic antidepressants). A 10-14 h fasting blood sample was collected to assess parameters related to hematology, clinical chemistry and serology. The clinical chemistry profile included glucose, sodium, potassium, chloride, $\mathrm{CO}_{2}$, blood urea nitrogen, creatinine, calcium, osmolality, aspartate aminotransferase, alanine aminotransferase, alkaline phosphatase, total bilirubin, total protein, and albumin. Hematology measurements included white blood cell (WBC) count, WBC with differential, red blood cell count, hemoglobin, hematocrit, mean corpuscular volume, mean corpuscular hemoglobin concentration, and platelet count. The urinalysis included $\mathrm{pH}$, specific gravity, ketones, protein, glucose, bilirubin, urobilinogen, blood, leukocytes, and microscopic examination of urine (if results of in clinic dipstick were positive). Serology was also performed and included HBsAg, hepatitis C antibody, and HIV 1/0/2 antibodies. Other tests included urinalysis for drug screen, a breath alcohol test, a physical examination, and a 12-lead electrocardiogram (EKG). All clinical laboratory measurements were performed by Elmhurst Memorial Hospital (Elmhurst, IL).

At study Visit 2, eligible subjects were reassessed for inclusion/exclusion criteria to confirm that all subjects met the study requirements, blood samples were taken to establish a baseline $(t=-0.75 h \pm 5 \mathrm{~min}$ ), and vital signs, use of drugs of abuse, and body weight were assessed on subjects meeting all requirements. The blood samples for the pharmacokinetic analysis were collected at $0.5,1,1.5,2,3,4,6,8,12,24,48$ and $72 \mathrm{~h}$ ( $\pm 5 \mathrm{~min})$ after dosing. Subjects remained in the clinic for the first $12 \mathrm{~h}$ after dosing, and were released after the $12 \mathrm{~h}$ blood draw. Subjects returned the following three mornings (Visits 3,4 and 5) for the $24 \mathrm{~h}, 48 \mathrm{~h}$ and $72 \mathrm{~h}$ blood sample collections. Subjects returned to the clinic for a follow-up visit (Visit 6) between 5 and $10 \mathrm{~d}$ after the end of the test period for final assessment of body weight, vital signs, use of drugs of abuse, and concomitant medication/supplement use. A final fasting (10-14 h) blood 
sample was collected to assess clinical chemistry and hematology parameters. In addition urinalysis, a physical examination and a 12-lead EKG were performed.

\subsubsection{Pharmacokinetic analysis}

Analysis for plasma steviol and steviol glucuronide was performed by WIL Research (Ashland, $\mathrm{OH})$ using LC-MS/MS. Plasma samples for the pharmacokinetic testing were shipped on dry ice to WIL Research (Ashland, OH). The LLOQ for steviol and steviol glucuronide were 20 and $4 \mathrm{ng} / \mathrm{mL}$, respectively. The same as for the rat study.

\subsubsection{Adverse events monitoring}

Adverse events (AEs) were recorded throughout the study at the beginning and end of each relevant visit (Visits 2-6), and the inquiries occurred with an open-ended question. AE is defined as any untoward medical occurrence in a clinical investigation subject that occurs after the administration of a study drug or product, and that does not necessarily have a causal relationship with this study product. An AE can be any unfavorable or unintended sign (including an abnormal finding), symptom, or disease temporally associated with the use of an investigational product, whether or not related to the investigational product.

\subsubsection{Statistical analysis}

All statistical analyses were conducted using SAS for Windows (version 9.4, Cary, NC). Descriptive statistics (number of subjects, mean, standard error of the mean, standard deviation, median, interquartile limits, minimum and maximum) were assessed for each outcome variable. BLQ values were assigned a value of zero for the toxicokinetic and mean (SD) plasma concentration calculations. The AUCs were calculated for steviol and steviol glucuronide, using the linear trapezoidal rule of the standard non-compartmental analysis based on the method by Shiang (2004). The terminal elimination constant $\left(\lambda_{z}\right)$ was estimated via linear 
regression of time versus log concentration according to the methodology by Matos-Pita and Bernardo de Miguel (2005). Missing data were not imputed and only observed data were included in the statistical analyses.

\section{Results}

\subsection{Rats}

\subsubsection{Plasma concentrations of steviol and steviol glucuronide}

The mean concentrations (plus/minus the standard deviation) of steviol and steviol glucuronide in the plasma samples from animals administered stevioside at doses of 40 or $1,000 \mathrm{mg} / \mathrm{kg}$ bw are provided in Tables 1 and 2. These values are plotted in Figures 2 and 3, respectively. Plasma steviol concentrations were below the limit of quantitation $(20 \mathrm{ng} / \mathrm{mL})$ for male and female rats administered $40 \mathrm{mg} / \mathrm{kg}$ bw at baseline, and at 0.5 and $1 \mathrm{~h}$ post-administration. Steviol concentrations were detectable in plasma samples from male and female rats at $2 \mathrm{~h}$ post-administration, and increased through 4 and $6 \mathrm{~h}$ post-administration $(76.0 \pm 36.5$ and 87.1 $\pm 42.2 \mathrm{ng} / \mathrm{mL}$, respectively), for males and females, respectively. Thereafter, plasma concentrations decreased through to 24 and $12 \mathrm{~h}$ post-administration, reaching non detectable levels by 36 and $24 \mathrm{~h}$ in males and females, respectively (Figure 2, top). Following administration of $1,000 \mathrm{mg} / \mathrm{kg}$ bw, plasma steviol concentrations were detected at $1 \mathrm{~h}$ postadministration and increased through 6 and $12 \mathrm{~h}$ post-administration (539 \pm 399 and 1,960 \pm $3,880 \mathrm{ng} / \mathrm{mL}$ ) in males and females, respectively. In male rats steviol concentrations generally decreased thereafter, with concentrations remaining constant between 12 and $24 \mathrm{~h}$ postadministration and reaching non detectable levels by $72 \mathrm{~h}$ post-administration. In females, plasma steviol concentrations decreased through to the last time point measured (Figure 3, top). 
In male and female rats, plasma steviol glucuronide concentrations were below the limit of quantitation $(4.0 \mathrm{ng} / \mathrm{mL})$ at baseline and $0.5 \mathrm{~h}$ post-administration of $40 \mathrm{mg} / \mathrm{kg}$ bw of stevioside. Plasma concentrations of steviol glucuronide were detected at $1 \mathrm{~h}$ post-administration and increased until 6 and $4 \mathrm{~h}$ post-administration (160 \pm 78.9 and $200 \pm 110 \mathrm{ng} / \mathrm{mL}$, respectively) in males and females, respectively. Steviol glucuronide remained detectable in the plasma until $48 \mathrm{~h}$ post-administration, decreasing to below limits of quantification at the last time point measured in both male and female rats (Figure 2, bottom). Following administration of 1,000 mg stevioside/kg bw, plasma concentrations of steviol glucuronide increased from 30 min postadministration through 8 and $12 \mathrm{~h}$ post-administration $(1,410 \pm 770$ and $6,650 \pm 13,400 \mathrm{ng} / \mathrm{mL}$, respectively) in males and females, respectively. Steviol glucuronide concentrations decreased thereafter, remaining detectable at $72 \mathrm{~h}$ post-administration in both males and females $(7.72 \pm$ 11.2 and $12.9 \pm 15.8 \mathrm{ng} / \mathrm{mL}$, respectively). Similar to plasma steviol concentrations, in males the steviol glucuronide concentrations remained constant between 12 and 24 h postadministration of both doses of stevioside (Figure 3, bottom). As can be seen from Table 2 and Figure 3 , there is significant variability (note the SD and error bars) in the $12 \mathrm{~h}$ data for female rats for both steviol and steviol glucuronide concentrations. This was due to the very high levels of both analytes in a single animal $(9,880 \mathrm{ng} / \mathrm{mL}$ steviol and $34,000 \mathrm{ng} / \mathrm{mL}$ steviol glucuronide). The relative ratios of these analytes, however, was similar to the rest of the animals sampled at this time interval.

\subsubsection{Toxicokinetics}

The $\mathrm{C}_{\max }$, the time of maximum observed plasma concentration, area under the curve to the last quantifiable observation ( $A \cup C_{\text {last }}$ ) and $\mathrm{T}_{1 / 2}$ for steviol and steviol glucuronide in males and females administered stevioside are summarized in Table 3. In the $40 \mathrm{mg} / \mathrm{kg}$ bw dose group, the toxicokinetic parameters for plasma steviol and steviol glucuronide were comparable between males and females. In the $1,000 \mathrm{mg} / \mathrm{kg}$ bw dose groups, the times to reach peak 
concentrations of steviol and steviol glucuronide was longer for females (12 h) in comparison to males ( 6 and $8 \mathrm{~h}$, respectively). Peak concentrations of steviol and steviol glucuronide also differed between males and females; $\mathrm{C}_{\max }$ for free steviol and steviol glucuronide was approximately 4- and 5-fold higher for females in comparison to males, respectively. The $A \cup C_{\text {last }}$ for both free steviol and steviol glucuronide was approximately 3-fold higher in females as compared to males. In comparison to the dose administered, a 25-fold increase in the stevioside dose resulted in 7- and 9-fold increases in $\mathrm{C}_{\max }$ and 16- and 13-fold increases in $\mathrm{AUC}_{\text {last }}$ for steviol and steviol glucuronide, respectively, in males. In females, a 25 -fold increase in stevioside dose resulted in 23- and 33-fold increases in $\mathrm{C}_{\max }$ and 42- and 32-fold increases in $A \cup C_{\text {last }}$ for steviol and steviol glucuronide, respectively. The $T_{1 / 2}$ of steviol also was longer in females in comparison to males, whereas the $T_{1 / 2}$ of steviol glucuronide was comparable between sexes. Greater concentrations of steviol glucuronide in comparison to steviol were detected in the plasma of male and female rats, with peak plasma concentrations being 2- to 3fold higher and total exposure being 4- to 3-fold higher in the 40 and 1,000 mg/kg bw dose groups, respectively.

As presented in Figures 4 and 5 , the relationship between dose and $\mathrm{C}_{\max }$ or $\mathrm{AUC}_{\text {last }}$ for females was linear, whereas for males, the dose-normalized values for $\mathrm{C}_{\max }$ and $\mathrm{AUC}_{\text {last }}$ were lower at the $1,000 \mathrm{mg} / \mathrm{kg}$ bw dose for both steviol and steviol glucuronide in comparison to the $40 \mathrm{mg} / \mathrm{kg}$ bw dose (Table 3 and Figure 5). The dose-dependent differences noted between the 40 and $1,000 \mathrm{mg} / \mathrm{kg}$ bw dose levels in toxicokinetic parameters for plasma steviol and stevioside in the high-dose group male rats is most likely a reflection of incomplete absorption of the bolus stevioside dose, rather than a saturation of the conjugation pathway because steviol and steviol glucuronide were similarly decreased at the higher dose level of $1,000 \mathrm{mg} / \mathrm{kg} \mathrm{bw}$ in males. The vehicles used for the 40 and 1,000 mg/kg bw groups, were deionized water and PEG400
Commented [a1]: Andy do you think we need to delete these 2 sentences as the third reviewer obviously interpreted this as meaning a gender difference. 
respectively, but this cannot explain the difference in dose-normalized $\mathrm{C}_{\max }$ or $\mathrm{AUC}_{\text {last }}$ values between males and females.

\subsection{Humans}

\subsubsection{Subject characteristics}

All subjects enrolled in the study were included in the Safety, Efficacy Evaluable (EE) and first Per Protocol (PP1) populations. One subject was excluded from the second Per Protocol (PP2) population due to baseline values of steviol glucuronide being outside of 1.5 -fold the interquartile range (IQR) (6 of 10 subjects had LC-MS/MS signals equivalent to quantifiable amounts of steviol glucuronide present at baseline). No subjects had LC-MS/MS signals equivalent to detectable concentrations of free steviol at baseline. The demographics of the EE and PP1 populations are summarized in Table 4. The PP2 population had very similar demographic characteristics. The 10 male subjects had an average age of 29.4 years and a mean body mass index of $24.4 \mathrm{~kg} / \mathrm{m}^{2}$.

\subsubsection{Pharmacokinetic results}

Plasma steviol was detected in nine out of ten subjects within the EE and PP1 populations, with one subject having plasma levels below the lower limit of quantification $(20 \mathrm{ng} / \mathrm{mL})$ at all time points. In the PP2 population, plasma steviol was detected in eight of the nine subjects. As mentioned previously, one subject was excluded from the PP2 population due to baseline values of steviol glucuronide being outside of 1.5 -fold the IQR. Steviol glucuronide was detected in the plasma of all study participants following administration of stevioside.

The mean concentrations (plus/minus the standard deviation) of steviol and steviol glucuronide in the plasma samples from subjects administered $40 \mathrm{mg}$ stevioside/kg bw are provided in Table 5. The time-concentration curves are presented in Figure 6. The results include those for the 
EE/PP1 populations as well as the PP2 (PP1 population minus the subject with steviol glucuronide values in excess of 1.5 -fold the IQR)

The pharmacokinetic parameters for steviol and steviol glucuronide following stevioside administration are presented in Table 6. Peak plasma concentrations of steviol and steviol glucuronide were observed 19-20 $\mathrm{h}$ and 21-22 $\mathrm{h}$ following administration of $40 \mathrm{mg} / \mathrm{kg} \mathrm{bw}$ stevioside, respectively. The maximum plasma concentrations of steviol glucuronide $(4,470$ $\mathrm{ng} / \mathrm{mL}$, EE and PP1; 4,400 ng/mL, PP2) were higher than that of steviol $(77.2 \mathrm{ng} / \mathrm{mL}, \mathrm{EE}$ and PP1; 72.5 PP2). Plasma concentrations of steviol were below the limit of quantification approximately $48 \mathrm{~h}$ after dosing among 7 subjects in EE and PP1 and 6 subjects in PP2. The terminal $T_{1 / 2}$ of steviol was estimable for one subject (15.4 h) because the $\lambda_{z}$ was inestimable for the remainder of the subjects in EE, PP1 and PP2. For steviol glucuronide, by the end of the experiment, $72 \mathrm{~h}$ after dosing, detectable amounts were still present in the plasma of all subjects $(663 \pm 902 \mathrm{ng} / \mathrm{mL})$ (Table 5$)$. The terminal $T_{1 / 2}$ for steviol glucuronide was estimated to be about $18.6 \mathrm{~h}$ in the EE/PP1 population and $18.8 \mathrm{~h}$ in the PP2 population.

The area under the plasma concentration-time curve (AUC) from pre-administration $(-0.75 \mathrm{~h})$ to 24, 48 and $72 \mathrm{~h}$ post-administration for steviol and steviol glucuronide increased over each time point. As presented in Table 7, the ratios of plasma steviol glucuronide to steviol for AUC-0.75-24h, AUC-0.75-48h, and $\mathrm{AUC}_{-0.75-72 \mathrm{~h}}$ were similar, and range between 86.8 and 99.7 for EE and PP1 and 90.3 and 99.4 for PP2. Estimated area AUC from time zero to infinity ( $A \cup C_{-0.75-\text { inf }}$ ) for steviol was estimable for one subject; therefore the ratio of steviol glucuronide to steviol for AUC-0.75-inf could not be determined. 


\subsubsection{Safety results}

Nausea was reported by one subject between screening and Visit 2 and resolved prior to consumption of the test material. Therefore, this was not an intervention-emergent adverse event. No other adverse events were reported during the study.

\section{Discussion and Conclusions}

Similar toxicokinetic parameters for steviol and steviol glucuronide were observed between male and female rats administered stevioside at a dose of $40 \mathrm{mg} / \mathrm{kg}$ bw (Table 3) with plasma concentrations of steviol glucuronide detected in greater amounts than that of steviol. The second dose group included in the rat study $(1,000 \mathrm{mg} / \mathrm{kg} \mathrm{bw})$ was used to determine whether glucuronidation could be saturated in rats following high doses of steviol glycosides similar to those used in toxicity studies, thereby resulting in disproportionally higher free steviol concentrations at toxic doses. A linear relationship between dose and peak plasma concentrations and dose and exposure of steviol and steviol glucuronide was noted among female rats. In contrast a non-linear relationship was observed in male rats (Figure 5); because both steviol and steviol glucuronide were equally affected, saturation of the glucuronidation pathway in males is not indicated. As a consequence, there is no gender-specific effect on the levels of glucuronidation rather, it is likely that the non-linear relationship in males is due to incomplete absorption of the bolus dose, but a vehicle effect is not suspected because females were not affected.

In 10 healthy males (29.40 years; BMI $24.40 \mathrm{~kg} / \mathrm{m}^{2}$ ) administered a single dose of stevioside at $40 \mathrm{mg} / \mathrm{kg} \mathrm{bw}$, the concentrations of steviol and steviol glucuronide in the plasma increased, reaching peak concentrations after 19-20 and 21-22 h, respectively (see Table 6). The ratio of peak plasma concentrations of steviol glucuronide in comparison to steviol was approximately 71 for EE and PP1, and 75 for PP2 (Table 7). The reason for the differences among the 
population groups was the exclusion of one subject with baseline values of steviol glucuronide being outside of $1.5^{\star} \mid Q R$. The exposure to steviol glucuronide over the course of the study, as

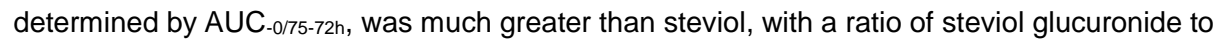
steviol of approximately 99.

The peak concentrations in humans occurred slightly later than in rats where $C_{\max }$ values for steviol and steviol glucuronide occurred 4 and 8-12 h post-dosing, respectively. At a dose 40 $\mathrm{mg} / \mathrm{kg}$, in humans, peak concentrations of steviol were similar to those in rats, while peak concentrations of the glucuronide conjugate were approximately 25 -fold greater than in the rat (i.e., $4,400 \mathrm{ng} / \mathrm{mL}$ vs. $180 \mathrm{ng} / \mathrm{mL}$ ) (see Tables 3 and 6).

At $40 \mathrm{mg} / \mathrm{kg}$ bw, the systemic exposures, as measured by the $\mathrm{AUC}_{0.75-72 \mathrm{~h}}$ of humans to steviol $\left(\sim 1,650 \mathrm{ng}^{\star} \mathrm{h} / \mathrm{mL}\right)$ were about 2.8 -fold greater than in rats $\left(\sim 590 \mathrm{ng}{ }^{\star} \mathrm{h} / \mathrm{mL}\right)$. For steviol glucuronide, systemic exposures in humans were approximately 57-fold higher ( 136,000 $\mathrm{ng}^{\star} \mathrm{h} / \mathrm{mL}$ vs. $\sim 2,400 \mathrm{ng}^{\star} \mathrm{h} / \mathrm{mL}$ ). As a result, the ratio of the AUC of steviol glucuronide/free steviol is much lower in rats (i.e., 4 ) than in humans (i.e., 90). This result indicates that the extent of glucuronidation is higher in humans than in rats.

The results from the present study are consistent with those from earlier studies examining the toxicokinetics/pharmacokinetics of steviol glycosides following oral administration which identified steviol and steviol glucuronide in the plasma of rat and humans (Geuns, 2007; Roberts and Renwick, 2008; Wheeler et al., 2008).

The study of Roberts and Renwick (2008) identified differences in the circulating concentrations of steviol and steviol glucuronide in the plasma of rats, with low concentrations of steviol glucuronide, such that the ratio of plasma concentrations of steviol glucuronide to steviol were approximately 0.1-0.2 in male and female rats (compared with $\sim 4$ in the present study).

Compared to the current study, on a dose normalized basis ( $4.2 \mathrm{mg} / \mathrm{kg} v \mathrm{~s} .40 \mathrm{mg} / \mathrm{kg}$ ) actual 
$\mathrm{C}_{\max }$ values for steviol concentrations in the Roberts and Renwick (2008) study were higher by about 4- to 6-fold while steviol glucuronide concentrations were about 4-fold lower. The most probable reasons for the difference in the ratio of plasma concentrations of steviol glucuronide to steviol between the present study and that conducted by Roberts and Renwick (2008), were the analytical methods used for analyzing plasma concentration (LC/MS/MS versus TLC and liquid scintillation counting) and possibly the stability of steviol glucuronide in plasma during sample processing in Roberts and Renwick (2008).

The results of the current human toxicokinetic study broadly compare with those reported by Wheeler et al. (2008). Wheeler et al. (2008) identified free steviol above the limit of quantification (LOQ, $100 \mathrm{ng} / \mathrm{mL}$ ) in only one individual at one time point following administration of stevioside at a dose of $4.2 \mathrm{mg} / \mathrm{kg}$ bw. Interestingly, in the current study, free steviol was detected, at mean maximum concentrations of approximately $77 \mathrm{ng} / \mathrm{mL}$, in nine out of ten individuals, and most (all but four samples) of the observed concentrations would have been undetectable by Wheeler et al. (2008) as they were below the LOQ of $100 \mathrm{ng} / \mathrm{mL}$ in that particular study. Hence, it is difficult to compare $C_{\max }$ and $A U C$ values reported here with the very limited steviol data available from Wheeler et al. (2008). In the Wheeler et al. (2008) study, following a $4.2 \mathrm{mg} / \mathrm{kg}$ bw dose of stevioside, the $\mathrm{C}_{\max }$ and $\mathrm{AUC}_{0-\mathrm{t}}$ values for steviol glucuronide were reported as $1,886 \mathrm{ng} / \mathrm{mL}$ and $34,090 \mathrm{ng}{ }^{\star} \mathrm{h} / \mathrm{mL}$, respectively, as geometric means. In comparison to the current study, these values, on a dose-normalized basis are about 4-fold and 2.5-fold higher, respectively. However, limitations in the analytical procedures and sensitivity used by Wheeler et al. (2008) restrict the comparison of these parameters both with the current studies in rats and humans and with the rat study by Roberts and Renwick (2008). Therefore, the data generated from the current study, for both rats and humans, are more reliable and internally comparable relative to the data generated from earlier studies (Roberts and Renwick, 2008; Wheeler et al., 2008). Given the use of similar analytical methodology, the current 
toxicokinetic studies provide data for robust inter-species comparisons of the toxicokinetics of steviol/steviol glucuronide in rats and man.

It is generally expected that the $A \cup C_{\text {last }}$ in humans to be higher than that in rats of most chemicals given the same dose level (WHO, 2005). Moreover, the plasma clearance of most chemicals is lower in humans than in rodents (WHO, 2005). Consistent with this was the finding, on equal dose basis, of an approximately 2.8-fold higher $\mathrm{AUC}_{0.75-72 \mathrm{~h}}$ for steviol in humans compared to rats. The finding of this 2.8 -fold difference in absolute systemic exposures is notable in relation to the establishment of an ADI for steviol glycosides. In the derivation of an ADI from animal data, a 10-fold uncertainty factor is applied for possible, undefined interspecies differences; this 10 -fold factor can be subdivided into a 4-fold uncertainty factor to allow for inter-species toxicokinetic differences and a 2.5 -fold uncertainty factor to account for interspecies toxicodynamic differences (WHO, 2005). The default uncertainty factor of 10 is used when data-derived comparisons are not available. However, if suitable toxicokinetic data are available to define the inter-species differences the WHO has stated that CSAF can be used when deciding upon the appropriate total uncertainty factor to apply to the NOAEL in order to derive the ADI (WHO, 2005).

To determine the appropriate CSAF to account for the toxicokinetic differences between rats and humans following administration of steviol glycosides, both the AUC and the $\mathrm{C}_{\text {max }}$ values following administration of the same dose ( $40 \mathrm{mg} / \mathrm{kg} \mathrm{bw}$ ) may be used. Since the ADI for steviol glycosides is based on a chronic dietary study, as opposed to an acute effect, the use of AUC as a surrogate of exposure in relation to toxicity may be preferable to $C_{\max }$ (Renwick and Lazarus, 1998; Meek et al., 2002). The AUC from time 0 to infinity $\left(A U_{0-\infty}\right)$ for steviol could not be calculated for all datasets within the $40 \mathrm{mg} / \mathrm{kg}$ rat study because concentrations of steviol were below the limit of detection after $24 \mathrm{~h}$. In the human study concentrations of steviol were below the limit of detection by $72 \mathrm{~h}$ (the last sampling point) in all but one subject (Table 5). 
Therefore, for valid comparisons, the $\mathrm{AUC}_{\text {last }}$ was used for rat data and the $\mathrm{AUC}_{0-72}$ value was used for humans. In comparing the toxicokinetic parameters from the recent study, the $\mathrm{AUC}_{0-72}$ for free steviol in humans $(1,631 \mathrm{ng} \cdot \mathrm{h} / \mathrm{mL})$ is higher than the $A U C_{\text {last }}$ in male and female rats (581 and $605 \mathrm{ng} \cdot \mathrm{h} / \mathrm{mL}$, respectively), and the ratio of AUC between humans and rats is 2.8 . Conversely, the $\mathrm{C}_{\max }$ values in humans $(77.21 \mathrm{ng} / \mathrm{mL})$ are approximately equivalent to those in male and female rats $\left(76.0\right.$ and $87.1 \mathrm{ng} / \mathrm{mL}$, respectively, so that the ratio of $C_{\max }$ values between humans and rats is approximately one. Saturation of glucuronidation in humans is unlikely because this is a high-capacity pathway, because at doses of $40 \mathrm{mg} / \mathrm{kg}$ the interspecies $\mathrm{C}_{\text {max }}$ ratio is lower than the AUC ratio and because there is no evidence in rats of saturation of glucuronidation comparing $40 \mathrm{mg} / \mathrm{kg}$ and $1,000 \mathrm{mg} / \mathrm{kg}$ doses.

The ratios between human and rats, derived from the current specifically-designed studies, for both the $A \cup C$ and $C_{\max }(2.8$ and 1, respectively) are lower than the default uncertainty factor of 4.0 for interspecies toxicokinetic differences (WHO, 2005). In consequence, the current 100fold safety applied to the NOAEL from a chronic rat study to establish the ADI for steviol glycosides may be unduly conservative since it assumes the default factor of 4.0 for toxicokinetic differences between species. Therefore, the default uncertainty factor for interspecies differences when calculating the ADI for steviol glycosides can be revised to range from 2.5 ( 1 for toxicokinetic differences based on $\mathrm{C}_{\max }$ values in rat and man $\times 2.5$ for toxicodynamic differences) to 7 (2.8 for toxicokinetic differences based on AUC values in rat and man $\times 2.5$ for toxicodynamic differences) based on the use of $C_{\max }$ and $A U C$ ratios, respectively. This interspecies, toxicokinetic CSAF (chemical-specific adjustment factor) can be used to replace the default uncertainty factor of 4.0. As a result, the normal 100-fold uncertainty factor, (comprising the default factor of 10 for inter-species differences normally applied to a toxicology study NOAEL, and the 10-fold factor to account for human variability), can be replaced by either 70 (i.e., $2.8 \times 2.5$ [for inter-species pharmacodynamics differences] x 10 rather than $4 \times 2.5 \times 10$ ) 
based on AUC data from rats and humans or 25 (i.e., $1.0 \times 2.5 \times 10$ rather than $4 \times 2.5 \times 10$ ) based on. This uncertainty factor can be reduced further to 1 based on comparative $C_{\max }$ data from rats and man. As a consequence using a CSAF supports a higher ADI value for steviol glycosides of 6 to $16 \mathrm{mg} / \mathrm{kg} \mathrm{bw} / \mathrm{d}$ depending upon the use of either AUC or $\mathrm{C}_{\max }$ data, when using the $400 \mathrm{mg} / \mathrm{kg} / \mathrm{d}$ NOAEL from the chronic study on stevioside (Toyoda et al., 1997).

The increase in ADI based upon the CSAF is further corroborated through results of a number of subchronic toxicity studies in which the steviol glycoside rebaudioside A was administered in the diet at dosages up to 50,000 ppm (Curry and Roberts, 2008; Nikiforov and Eapen, 2008). The NOAEL in the 13-week study conducted by Curry and Roberts (2008) was reported to be 4,161 and 4,645 mg/kg bw/d in male and female Wistar rats respectively, the highest dose tested, which is equivalent to 1,373 and $1,532 \mathrm{mg} / \mathrm{kg}$ bw/ $\mathrm{d}$ steviol equivalents. A preliminary 4week study was also conducted at levels up to 100,000 ppm which resulted in mean achieved dosages of between 14,167 and 11,672 and 14,119 and 13,126 mg/kg bw/d between weeks 1 and 4 for males and females respectively. Again, there were no adverse reactions to high dose administration other than effects on body weight gain which would be anticipated given the caloric dilution of the diet at dosages in excess of $4,000 \mathrm{mg} / \mathrm{kg} \mathrm{bw} / \mathrm{d}$ steviol equivalents.

While subchronic studies are not routinely used to derive an ADI, the results of such studies are useful in predicting potential effects in chronic studies (Luijten et al., 2012) and in the case of stevioside support the lack of adverse findings in the Toyoda et al., 1997 study. The available subchronic toxicity studies on steviol glycosides show that the current ADI for steviol glycosides (0-4 $\mathrm{mg} / \mathrm{kg} / \mathrm{d})$ can be viewed as being conservative since no adverse findings have been detected in any of the studies conducted to date at dose levels supporting a significantly higher ADI, even when using a 200-fold default safety factor (EFSA, 2012). The only effects noted in the steviol glycoside animal toxicity studies have been related to decreases in body weight gain, which have previously been described for a number of other sweetener products including 
sucralose and neotame as result of palatability, caloric reduction, and subtle decrements in food consumption at study initiation (Carakostas et al., 2008). The results reported in the Toyoda et al. (1997) publication which is the study that has been used historically to derive the ADI for steviol glycosides, may also support a higher ADI. The authors considered the mid dose to be the NOAEL on the basis that the top dose had a slightly reduced body weight gain and a significant decrease in survival rate. However, as noted, it is not uncommon for slight reductions in body weight gain in studies involving high intensity sweeteners in general. The decrease in survival was postulated to result from an increase in large granular lymphocytic type leukemia which was a common finding in the testing laboratory as well as in all laboratories using the F344 rat. Since the incidence of large granular lymphocytic type leukemia was found to be within the historical control range and given that noting that the presence of this neoplasm is now interpreted quite differently (Thomas et al., 2007) than at the time of the Toyoda et al. (1997), there is no indication of a treatment-related effect. In addition, as recently discussed by Maronpot et al. (2016), this neoplasm is a result of the species-strain specific biology of the F344 rat and is of little relevance to human risk assessment. As such it could be argued that in reality the top dose of $5 \%$ in the study was the true NOAEL, which equates to a dose level of $1,997 \mathrm{mg} / \mathrm{kg}$ bw/d in males and 2,387 mg/kg bw/d in females. This NOAEL equates to about $800 \mathrm{mg}$ steviol equivalents $/ \mathrm{kg}$ bw/d and using the standard 100 -fold uncertainty factor, would increase the ADI to $8 \mathrm{mg}$ steviol equivalents $/ \mathrm{kg}$ bw/d, while the CSAF-derived total uncertainty factors of 70 or 25 would give ADI vales of 11 or $32 \mathrm{mg}$ steviol equivalents $/ \mathrm{kg} \mathrm{bw} / \mathrm{d}$.

In conclusion, both the reduction in the uncertainty safety factor from a default value of 10 to a value of 7 using the AUC-based CSAF, reconsideration of the NOAEL in the Toyoda et al. (1997) study, along with the higher NOAELs from additional subchronic studies including those conducted with rebaudioside A (Curry and Roberts, 2008), support an increased ADI for steviol glycosides. The ADI using the CSAF would range between 6 and $16 \mathrm{mg} / \mathrm{kg} / \mathrm{d}$ using the AUC 
and $\mathrm{C}_{\max }$ data, whereas the ADI using the animal subchronic studies ranges between 7 and 20 $\mathrm{mg} / \mathrm{kg} \mathrm{bw} / \mathrm{d}$ steviol equivalents based on 13- and 4-week rat studies, respectively. The CSAF taken together with the higher NOAEL of $800 \mathrm{mg}$ steviol equivalents $/ \mathrm{kg}$ bw/d from the Toyoda et al. (1997) study yields an ADI range of 12 to $32 \mathrm{mg} / \mathrm{kg} / \mathrm{d}$ using the AUC and $\mathrm{C}_{\max }$ data, respectively. 


\section{Figure captions}

Figure 1. Steviol-based backbone structure of steviol glycosides

Figure 2. Mean $( \pm S D)$ concentrations ${ }^{*}$ of steviol and steviol glucuronide in plasma of male and female rats following oral administration of stevioside at $40 \mathrm{mg} / \mathrm{kg}$

* See Table 1 for the number of individual animals with quantifiable concentrations.

Figure 3. Mean $( \pm S D)$ concentrations* of steviol and steviol glucuronide in plasma of male and female rats following oral administration of stevioside at $1,000 \mathrm{mg} / \mathrm{kg}$

*See Table 2 for the number of individual animals with quantifiable concentrations.

Figure 4. Area under the plasma concentration-time curves $\left(\mathrm{AUC}_{\text {last }}\right)$ and peak plasma concentrations $\left(\mathrm{C}_{\max }\right)$ for steviol and steviol glucuronide following oral administration of stevioside at 40 or $1,000 \mathrm{mg} / \mathrm{kg}$ to male and female rats

Figure 5. Dose-normalized area under the plasma concentration-time curves (AUClast) and peak plasma concentrations $\left(\mathrm{C}_{\max }\right)$ for steviol and steviol glucuronide following oral administration of stevioside at 40 or $1,000 \mathrm{mg} / \mathrm{kg}$ to male and female rats

Figure 6. Mean $( \pm S D)$ concentrations* of steviol and steviol glucuronide in plasma of human male subjects following oral administration of stevioside at $40 \mathrm{mg} / \mathrm{kg}$

* See Table 5 for the number of individual subjects with quantifiable concentrations. 


\section{References}

Carakostas MC, Curry LL, Boileau AC, Brusick DJ., 2008. Overview: the history, technical function and safety of rebaudioside A, a naturally occurring steviol glycoside, for use in food and beverages. Food Chem Toxicol 46 (7, Suppl.), S1-S10. DOI:10.1016/j.fct.2008.05.003.

Ceunen, S., Geuns, J.M.C., 2013. Steviol glycosides: chemical diversity, metabolism, and function. J. Nat. Prod. 76, 1201-1228. DOI:10.1021/np400203b.

Chaturvedula, V.S.P., Prakash, I., 2011a. Additional minor diterpene glycosides from Stevia rebaudiana. Nat. Prod. Commun. 6, 1059-1062. DOI:10.3390/molecules181113510.

Chaturvedula, V.S.P., Prakash, I., 2011b. Structures of the novel diterpene glycosides from Stevia rebaudiana. Carbohydr. Res. 346, 1057-1060. DOI:10.1016/j.carres.2011.03.025.

Chaturvedula, V.S.P., Rhea, J., Milanowski, D., Mocek, U., Prakash, I., 2011a. Two minor diterpene glycosides from the leaves of Stevia rebaudiana. Nat Prod. Commun. 6, 175-178.

Chaturvedula, V.S.P., Upreti, M., Prakash, I., 2011b. Structures of the novel a-glucosyl linked diterpene glycosides from Stevia rebaudiana. Carbohydr. Res. 346, 2034-2038.

DOI:10.1016/j.carres.2011.06.023.

Chaturvedula, V.S.P., Upreti, M., Prakash, I., 2011c. Diterpene glycosides from Stevia rebaudiana. Molecules 16(5), 3552-3562. DOI:10.3390/molecules16053552.

Curry LL, Roberts A., 2008. Subchronic toxicity of rebaudioside A. Food Chem Toxicol 46 (7, Suppl.), S11-S20. DOI:10.1016/j.fct.2008.04.042.

EFSA, 2012. Guidance on selected default values to be used by the EFSA Scientific Committee, Scientific Panels and Units in the absence of actual measured data. (EFSA 
Scientific Committee) (Question no EFSA-Q-2010-00221, adopted on 8 February 2012).

European Food Safety Authority (EFSA), Parma, Italy. EFSA J.10 (3), 2579.

DOI:10.2903/j.efsa.2012.2579. Available at:

<http://www.efsa.europa.eu/en/efsajournal/pub/2067.htm>.

EFSA, 2015. Scientific opinion on the safety of the proposed amendment of the specifications for steviol glycosides (E 960) as a food additive (EFSA Panel on Food Additives and Nutrient Sources/ANS) (Question No. EFSA-Q-2014-00002), adopted 17 November 2015). EFSA J. 13 (12), 4316. [28 pp.]. DOI:10.2903/j.efsa.2015.4316. Available at:

$<$ http://www.efsa.europa.eu/en/efsajournal/pub/4316.htm $>$.

Gardana, C., Simonetti, P., Canzi, E., Zanchi, R., Pietta, P., 2003. Metabolism of stevioside and rebaudioside A from Stevia rebaudiana extracts by human microflora. J. Agric. Food Chem. 51, 6618-6622. DOI:10.1021/jf0303619.

Geuns, J.M.C., 2007. Comments to the paper by Nunes et al. (2007), Analysis of genotoxic potentiality of stevioside by comet assay, Food and Chemical Toxicology 45 (2007) 662-666 [Including response from A.P.M. Nunes et al.]. Food Chem. Toxicol. 45, 2601-2604.

DOI:10.1016/j.fct.2007.06.027.

Geuns, J.M., Augustijns, P., Mols, R., Buyse, J.G., Driessen, B., 2003. Metabolism of stevioside in pigs and intestinal absorption characteristics of stevioside, rebaudioside A and steviol. Food Chem. Toxicol. 41, 1599-1607. DOI:10.1016/S0278-6915(03)00191-1.

Geuns, J.M., Buyse, J., Vankeirsbilck, A., Temme, E.H., Compernolle, F., Toppet, S., 2006 Identification of steviol glucuronide in human urine. J. Agric. Food Chem. 5, 2794-2798.

DOI:10.1021/jf052693e. 
Geuns, J.M.C., Buyse, J., Vankeirsbilck, A., Temme, E.H.M., 2007. Metabolism of stevioside by healthy subjects. Exp. Biol. Med. Soc. Exp. Biol. Med. 232, 164-173.

Hutapea, A.M., Toskulkao, C., Buddhasukh, D., Wilairat, P., Glinsukon, T., 1997. Digestion of stevioside, a natural sweetener, by various digestive enzymes. J. Clin. Biochem. Nutr. 23, 177186. DOI:10.3164/jcbn.23.177.

JECFA, 2000. Sweetening agent: stevioside. In: Evaluation of Certain Food Additives. 51st Report of the Joint FAO/WHO Expert Committee on Food Additives. Geneva, Switzerland. WHO Technical Report Series 891, pp. 35-37. Available at: <http://apps.who.int/iris/bitstream/10665/42245/1/WHO TRS 891.pdf>.

JECFA, 2006. Steviol glycosides. In: Safety Evaluation of Certain Food Additives. 63rd Meeting of the Joint FAO/WHO Expert Committee on Food Additives, June 8-17, 2004, Geneva,

Switzerland. WHO Food Additives Series 54, pp. 117-144, 638. Available at:

<http://whqlibdoc.who.int/publications/2006/9241660546 eng.pdf>.

JECFA, 2007. Steviol glycosides. In: Evaluation of Certain Food Additives and Contaminants. 68th Report of the Joint FAO/WHO Expert Committee on Food Additives, Geneva, Switzerland. WHO Technical Report Series 947, pp. 50-54. Available at: <http://apps.who.int/iris/bitstream/10665/43870/1/9789241209472 eng.pdf>.

JECFA, 2009. Steviol glycosides: addendum. In: Safety Evaluation of Certain Food Additives. the 69th Meeting of the Joint FAO/WHO Expert Committee on Food Additives, Rome, Italy. WHO Food Additives Series 60, pp. 183-220. Available at: <http://apps.who.int/iris/bitstream/10665/44063/1/9789241660600 eng.pdf>.

Koyama, E., Kitazawa, K., Ohori, Y., Izawa, O., Kakegawa, K., Fujino, A., Ui, M., 2003a. In vitro metabolism of the glycosidic sweeteners, stevia mixture and enzymatically modified stevia in 
human intestinal microflora. Food Chem. Toxicol. 41, 359-374. DOI:10.1016/S0278-

6915(02)00235-1. DOI:10.1016/S0278-6915(02)00235-1.

Koyama, E., Sakai, N., Ohori, Y., Kitazawa, K., Izawa, O., Kakegawa, K., Fujino, A., Ui, M., 2003b. Absorption and metabolism of glycosidic sweeteners of stevia mixture and their aglycone, steviol, in rats and humans. Food Chem. Toxicol. 41, 875-873. DOI:10.1016/S02786915(03)00039-5.

Kraemer, T., Maurer, H.H., 1994. On the metabolism of the sweetener stevioside in humans. Eur. J. Pharm. Sci. 2, 103 (abstract no. FC12).

Luijten, M., Muller, J.J.A., Hernandez, L.G., van der Ven, L.T.M., van Benthem, J., 2012. Prediction of Carcinogenic Potential of Substances Using Repeated Dose Toxicity Data. (RIVM Report 340700006/2012). Rijksinstiuut Voor Volksgezondheid en Milieu (RIVM), Bilthoven, The Netherlands. Available at: < http://www.nkca.nl/object binary/05169 RIVM-report340700006[1].pdf >.

Maronpot, R., Nyska, A., Foreman, J., Ramot, Y., 2016. The legacy of the F344 as a cancer bioassay model (A retrospective summary of the three common F344 neoplasms). Food Chem. Toxicol. (submitted).

Matos-Pita, A.S., Bernardo de Miguel, L., 2005. Non-compartmental pharmacokinetics and bioequivalence analysis. In: PharmaSUG 2005. (May 22-25, 2005, Phoenix, AZ). SAS Institute Inc., Pharmaceutical Industry SAS® Users Group (PharmaSUG). (Paper SP07). Available at: $<$ http://www.lexjansen.com/pharmasug/2005/StatisticsPharmacokinetics/sp07.pdf >.

Meek, M.E., Renwick, A., Ohanian, E., Dourson, M., Lake, B., Naumann, B.D., Vu, V., 2002. Guidelines for application of chemical-specific adjustment factors in dose/concentrationresponse assessment. Toxicol. 181/182, 115-120. 
National Research Council, 2011. Guide for the Care and Use of Laboratory Animals, eighth edition. National Research Council, Division on Earth and Life Studies, Institute for Laboratory Animal Research, Committee for the Update of the Guide for the Care and Use of Laboratory Animals. National Academies Press (NAP), Washington, DC. Available at: <http://www.nap.edu/catalog/12910/guide-for-the-care-and-use-of-laboratory-animals-eighth> Nikiforov Al, Eapen AK., 2008. A 90-day oral (dietary) toxicity study of rebaudioside A in Sprague-Dawley rats. Int J Toxicol 27, 65-80. DOI:10.1080/10915810701876752.

Nikiforov, A.I., Rihner, M.O., Eapen, A.K., Thomas, J.A., 2013. Metabolism and toxicity studies supporting the safety of rebaudioside D. Int. J. Toxicol. 32, 261-273.

DOI:10.1177/1091581813492828.

Ohta, M., Sasa, S., Inoue, A., Tamai, T., Fujita, I., Morita, K., Matsuura, F., 2010.

Characterization of novel steviol glycosides from leaves of Stevia rebaudiana Morita. J. Appl. Glycosci. 57, 199-209.

Purkayastha, S., Pugh, G., Jr., Lynch, B., Roberts, A., Kwok, D., Tarka, S.M., Jr., 2014. In vitro metabolism of rebaudioside $\mathrm{B}, \mathrm{D}$, and $\mathrm{M}$ under anaerobic conditions: comparison with rebaudioside A. Regul. Toxicol. Pharmacol. 68, 259-268. DOI:10.1016/j.yrtph.2013.12.004.

Purkayastha, S., Bhusari, S., Pugh, G., Jr., Teng, X., Kwok, D., Tarka, SM., 2015. In vitro metabolism of rebaudioside $\mathrm{E}$ under anaerobic conditions: Comparison with rebaudioside $\mathrm{A}$. Regul. Toxicol. Pharmacol. 72, 646-657. DOI:10.1016/j.yrtph.2015.05.019.

Purkayastha, S., Markosyan, A., Prakash, I., Bhusari, S., Pugh, G. Jr, Lynch, B., Roberts, A., 2016. Steviol glycosides in purified stevia leaf extract sharing the same metabolic fate. Regul Toxicol Pharmacol. 77, 125-133. DOI:10.1016/j.yrtph.2016.02.015. 
Renwick, A.G., Lazarus, N.R., 1998. Human variability and noncancer risk assessment-An analysis of the default uncertainty factor. Regul. Toxicol. Pharmacol. 27 (1, Part 1), 3-20. DOI:10.1006/rtph.1997.1195.

Renwick, A.G., Tarka, S.M., 2008. Microbial hydrolysis of steviol glycosides. Food Chem. Toxicol. 46 (7, Suppl.), S70-S74. DOI:10.1016/j.fct.2008.05.008.

Roberts, A., Renwick, A.G., 2008. Comparative toxicokinetics and metabolism of rebaudioside A, stevioside, and steviol in rats. Food Chem. Toxicol. 46(7, Suppl.), S31-S39.

DOI:10.1016/j.fct.2008.05.006.

Shiang, K.D., 2004. The SAS® calculations of areas under the curve (AUC) for multiple metabolic readings. In: WUSS 2004, Oct. 13-15, 2004, Pasadena, CA. SAS Institute Inc., SAS User Group of the Western Region of the United States. Available at: $<$ http://www.lexjansen.com/wuss/2004/posters/c post the sas calculations .pdf $>$.

Simonetti, P., Gardana, C., Bramati, L., Pietta, P.G., 2004. Bioavailability of stevioside from Stevia rebaudiana in humans: preliminary report. In: Geuns JMC, Buyse J, editors. Safety of Stevioside: Proceedings of the First Symposium Sponsored by KULeuven, April 16, 2004, Leuven, Belgium. Euprint ed., Heverlee, Belgium, pp. 51-62.

Thomas, J., Haseman, J.K., Goodman, J.I., Ward, J.M., Loughran, T.P., Jr., Spencer, P.J., 2007. A review of large granular lymphocytic leukemia in Fischer 344 rats as an initial step toward evaluating the implication of the endpoint to human cancer risk assessment. Toxicol. Sci. 99, 3-19. DOI:10.1093/toxsci/kfm098.

Toyoda K, Matsui H, Shoda T, Uneyama C, Takada K, Takahashi M., 1997. Assessment of the carcinogenicity of stevioside in F344 rats. Food Chem Toxicol 35, 597-603.

DOI:10.1016/S0278-6915(97)00023-9. 
U.S. FDA, 2015. Part 58-Good laboratory practice for nonclinical laboratory studies. In: US Code of Federal Regulations (CFR). Title 21: Food and Drugs (US Food and Drug Administration). US Food and Drug Administration (US FDA), US Government Printing Office (GPO), Washington (DC). Available at: <http://www.accessdata.fda.gov/scripts/cdrh/cfdocs/cfcfr/CFRSearch.cfm?CFRPart=58>.

Wheeler, A., Boileau, A.C., Winkler, P.C., Compton, J.C., Prakash, I., Jiang, X., Mandarino, D.A., 2008. Pharmacokinetics of rebaudioside $A$ and stevioside after single oral doses in healthy men. Food Chem. Toxicol. 46 (7, Suppl.), S54-S60. DOI:10.1016/j.fct.2008.04.041.

WHO, 2005. Chemical-Specific Adjustment Factors for Interspecies Differences and Human Variability: Guidance Document for Use of Data in Dose/Concentration-Response Assessment. Harmonization Project Document No. 2. World Health Organization (WHO), Geneva. Available at: <http://www.inchem.org/documents/harmproj/harmproj/harmproj2.pdf >.

Wingard, R.E., Jr., Brown, J.P., Enderlin, F.E., Dale, J.A., Hale, R.L., Seitz, C.T., 1980.

Intestinal degradation and absorption of the glycosidic sweeteners stevioside and rebaudioside A. Experientia 36, 519-520. DOI:10.1007/BF01965774 
Table 1

Mean (SD) concentrations of steviol and steviol glucuronide of male and female rats following oral administration of stevioside at $40 \mathrm{mg} / \mathrm{kg}$ body weight

\begin{tabular}{|c|c|c|c|c|}
\hline \multirow[t]{2}{*}{ Time (hour) } & \multicolumn{2}{|l|}{ Male $(n=6)$} & \multicolumn{2}{|l|}{ Female $(n=6)$} \\
\hline & $\begin{array}{l}\text { Steviol }(\mathrm{ng} / \mathrm{mL})^{a} \\
\text { (no. quantifiable) }^{\mathrm{c}}\end{array}$ & $\begin{array}{l}\text { Steviol glucuronide } \\
(\mathrm{ng} / \mathrm{mL})^{\mathrm{b}} \\
\text { (no. quantifiable) }\end{array}$ & $\begin{array}{l}\text { Steviol (ng/mL) } \\
\text { (no. quantifiable) }\end{array}$ & $\begin{array}{l}\text { Steviol glucuronide } \\
\text { (ng/mL) } \\
\text { (no. quantifiable) }\end{array}$ \\
\hline 0 & BLQ & BLQ & $\mathrm{BLQ}$ & $B L Q$ \\
\hline 0.5 & BLQ & $B L Q$ & BLQ & $B L Q$ \\
\hline 1 & BLQ & $2.48 \pm 6.07(1)$ & BLQ & $0.709 \pm 1.74(1)$ \\
\hline 2 & $16.4 \pm 26.1$ (2) & $41.3 \pm 38.4(5)$ & $20.9 \pm 28.7$ (3) & $61.3 \pm 62.9(5)$ \\
\hline 4 & $76.0 \pm 36.5(6)$ & $115 \pm 58.5(6)$ & $82.4 \pm 36.3(6)$ & $200 \pm 110(6)$ \\
\hline 6 & $58.8 \pm 26.7(6)$ & $160 \pm 78.9(6)$ & $87.1 \pm 42.2(6)$ & $190 \pm 79.6(6)$ \\
\hline 8 & $30.6 \pm 21.1(5)$ & $112 \pm 63.8(6)$ & $50.3 \pm 36.3(5)$ & $171 \pm 87.6(6)$ \\
\hline 12 & $19.1 \pm 15.4(4)$ & $57.4 \pm 22.5(6)$ & $41.8 \pm 12.3(6)$ & $84.1 \pm 34.1(6)$ \\
\hline 24 & $7.12 \pm 17.4(1)$ & $53.9 \pm 57.0(6)$ & BLQ & $18.8 \pm 6.31(6)$ \\
\hline 36 & BLQ & $9.81 \pm 7.02(5)$ & BLQ & $17.1 \pm 10.9(6)$ \\
\hline 48 & BLQ & $21.9 \pm 18.9(6)$ & BLQ & $1.44 \pm 2.24(2)$ \\
\hline 72 & BLQ & BLQ & BLQ & $B L Q$ \\
\hline
\end{tabular}

$B L Q$, below limit of quantitation

a Limit of Quantitation, $20.0 \mathrm{ng} / \mathrm{mL}$

b Limit of Quantitation, $4.0 \mathrm{ng} / \mathrm{mL}$

c numbers of rats with quantifiable concentrations are noted in parenthesis

\section{Table 2}

Mean (SD) concentrations of steviol and steviol glucuronide of male and female rats following oral administration of stevioside at $1,000 \mathrm{mg} / \mathrm{kg}$ body weight

\begin{tabular}{|c|c|c|c|c|}
\hline \multirow[t]{2}{*}{ Time (hour) } & \multicolumn{2}{|l|}{ Male $(n=6)$} & \multicolumn{2}{|l|}{ Female $(n=6)$} \\
\hline & $\begin{array}{l}\text { Steviol }(\mathbf{n g} / \mathrm{mL})^{\mathrm{a}} \\
\text { (no. quantifiable) }^{\mathrm{c}}\end{array}$ & $\begin{array}{l}\text { Steviol } \\
\text { glucuronide } \\
(\text { ng/mL)b } \\
\text { (no. quantifiable) }\end{array}$ & $\begin{array}{l}\text { Steviol (ng/mL) } \\
\text { (no. quantifiable) }\end{array}$ & $\begin{array}{l}\text { Steviol } \\
\text { glucuronide } \\
\text { (ng/mL) } \\
\text { (no. quantifiable) }\end{array}$ \\
\hline 0 & $B L Q$ & BLQ & BLQ & BLQ \\
\hline 0.5 & BLQ & $6.07 \pm 4.67(5)$ & BLQ & $3.53 \pm 2.77(4)$ \\
\hline 1 & $56.4 \pm 34.5(6)$ & $99.3 \pm 44.4(6)$ & $77.5 \pm 53.5(5)$ & $159 \pm 134(5)$ \\
\hline 2 & $296 \pm 176(6)$ & $936 \pm 864(6)$ & $360 \pm 207(6)$ & $926 \pm 420(6)$ \\
\hline 4 & $292 \pm 79.1(6)$ & $990 \pm 589(6)$ & $491 \pm 370(6)$ & $1650 \pm 961(6)$ \\
\hline 6 & $539 \pm 339(6)$ & $709 \pm 266(6)$ & $763 \pm 644(6)$ & $2,600 \pm 2,060(6)$ \\
\hline 8 & $465 \pm 145(6)$ & $1,410 \pm 770(6)$ & $894 \pm 1,350(6)$ & $2,180 \pm 3,450(6)$ \\
\hline 12 & $252 \pm 187(6)$ & $740 \pm 782(6)$ & $1,960 \pm 3,880(6)$ & $6,550 \pm 13,400(6)$ \\
\hline 24 & $259 \pm 110(6)$ & $883 \pm 685(6)$ & $265 \pm 118(6)$ & $555 \pm 318(6)$ \\
\hline 36 & $46.8 \pm 31.2(5)$ & $129 \pm 93.9(6)$ & $54.8 \pm 47.0(5)$ & $200 \pm 152(6)$ \\
\hline 48 & $9.03 \pm 22.1$ (1) & $109 \pm 101(6)$ & $16.7 \pm 25.9(2)$ & $85.8 \pm 114(6)$ \\
\hline 72 & $\mathrm{BLQ}$ & $7.72 \pm 11.2(3)$ & $4.53 \pm 11.1(1)$ & $12.9 \pm 15.8(5)$ \\
\hline
\end{tabular}

$\mathrm{BLQ}$, below limit of quantitation

a Limit of Quantitation, $20.0 \mathrm{ng} / \mathrm{mL}$

b Limit of Quantitation, $4.0 \mathrm{ng} / \mathrm{mL}$ 
${ }^{c}$ numbers of rats with quantifiable concentrations are noted in parenthesis

Table 3

Summary of toxicokinetic parameters for steviol and steviol glucuronide in male and female rats following administration of stevioside at 40 or $1,000 \mathrm{mg} / \mathrm{kg}$ body weight

\begin{tabular}{|c|c|c|c|c|}
\hline \multirow[t]{2}{*}{ Parameter } & \multicolumn{2}{|l|}{$40 \mathrm{mg} / \mathrm{kg} \mathrm{bw}$} & \multicolumn{2}{|l|}{$1,000 \mathrm{mg} / \mathrm{kg} \mathrm{bw}$} \\
\hline & Males & Females & Males & Females \\
\hline \multicolumn{5}{|l|}{ Steviol } \\
\hline $\mathrm{C}_{\max }(\mathrm{ng} / \mathrm{mL})$ & $76.0(14.9)^{\mathrm{a}}$ & $87.1(17.2)$ & $539(163)$ & $1960(1580)$ \\
\hline 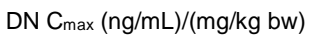 & 1.90 & 2.18 & 0.539 & 1.96 \\
\hline $\mathrm{T}_{\max }(\mathrm{h})$ & 4 & 6 & 6 & 12 \\
\hline$A \cup C_{\text {last }}\left(n^{\star}{ }^{*} / m L\right)$ & $581(81.5)$ & $605(66.7)$ & $9,290(918)$ & $25,700(12,800)$ \\
\hline $\begin{array}{l}\text { DN AUC last }\left(\mathrm{ng}^{*} \mathrm{~h} / \mathrm{mL}\right) /(\mathrm{mg} / \mathrm{kg} \\
\text { bw) }\end{array}$ & 14.5 & 15.1 & 9.29 & 25.7 \\
\hline $\mathrm{T}_{1 / 2}(\mathrm{~h})$ & 7.8 & NC & 5.0 & 10 \\
\hline \multicolumn{5}{|l|}{ Steviol glucuronide } \\
\hline $\mathrm{C}_{\max }(\mathrm{ng} / \mathrm{mL})$ & 160 (32.2) & $200(45.0)$ & $1,410(314)$ & $6,550(5,480)$ \\
\hline DN C $\max (n g / m L) /(m g / k g ~ b w) ~$ & 4.01 & 5.01 & 1.41 & 6.55 \\
\hline $\mathrm{T}_{\max }(\mathrm{h})$ & 6 & 4 & 8 & 12 \\
\hline $\mathrm{AUCl}_{\text {last }}\left(\mathrm{ng}^{*} \mathrm{~h} / \mathrm{mL}\right)$ & $2,310(316)$ & $2,500(204)$ & $29,200(4,470)$ & $79,700(44,100)$ \\
\hline $\begin{array}{l}\text { DN AUC last }\left(\mathrm{ng}^{*} \mathrm{~h} / \mathrm{mL}\right) /(\mathrm{mg} / \mathrm{kg} \\
\text { bw) }\end{array}$ & 57.7 & 62.5 & 29.2 & 79.7 \\
\hline$T_{1 / 2}(h)$ & NR & 6.5 & 7.5 & 8.9 \\
\hline
\end{tabular}

AUC, area under the plasma concentration-time curve; bw, body weight; $\mathrm{C}_{\max }$, peak concentration; DN, dosenormalized; NC, not calculable; NR, not reported; $\mathrm{T}_{1 / 2}$, half-life; $\mathrm{T}_{\max }$, time to reach maximum concentration a Mean (SEM)

Table 4

Baseline characteristics of study participants (EE and PP1 populations)

\begin{tabular}{ll}
\hline Characteristic & $\mathrm{n}(\%)$ \\
\hline White & $4(40.0)$ \\
African American & $2(20.0)$ \\
Asian or Pacific Islander & $2(20.0)$ \\
Multiracial origin & $2(20.0)$ \\
Other & $0(0.0)$ \\
& Mean \pm SEM \\
Age (years) & $29.40 \pm 2.57$ \\
Weight $(\mathrm{kg})$ & $75.67 \pm 4.65$ \\
BMI $\left(\mathrm{kg} / \mathrm{m}^{2}\right)$ & $24.40 \pm 1.00$ \\
Systolic BP $(\mathrm{mm} \mathrm{Hg})$ & $115.90 \pm 1.98$ \\
Diastolic BP $(\mathrm{mm} \mathrm{Hg})$ & $73.70 \pm 2.14$ \\
\hline
\end{tabular}


Heart rate (bpm)

$62.30 \pm 2.48$

\section{Table 5}

Mean \pm SD concentrations of steviol and steviol glucuronide of healthy male volunteers following consumption of stevioside at a dose of $40 \mathrm{mg} / \mathrm{kg}$ body weight

\begin{tabular}{|c|c|c|c|c|}
\hline \multirow[t]{2}{*}{ Time (hour) } & \multicolumn{2}{|c|}{ EE and PP1 Population ( $n=10$ total) } & \multicolumn{2}{|c|}{ PP2 Population ( $n=9$ total) } \\
\hline & $\begin{array}{l}\text { Steviol }(\mathrm{ng} / \mathrm{mL})^{a} \\
\text { (no. quantifiable) }^{\mathrm{c}}\end{array}$ & $\begin{array}{l}\text { Steviol glucuronide } \\
(\mathrm{ng} / \mathrm{mL})^{\mathrm{b}} \\
\text { (no. quantifiable) }\end{array}$ & $\begin{array}{l}\text { Steviol (ng/mL) } \\
\text { (no. quantifiable) }\end{array}$ & $\begin{array}{l}\text { Steviol glucuronide } \\
\text { (ng/mL) } \\
\text { (no. quantifiable) }\end{array}$ \\
\hline 0 & $\mathrm{BLQ}(0)$ & $48.0 \pm 74.6(6)$ & $\mathrm{BLQ}(0)$ & $27.4 \pm 38.7(5)$ \\
\hline 0.5 & $\operatorname{BLQ}(0)$ & $56.1 \pm 88.7(6)$ & $\operatorname{BLQ}(0)$ & $31.3 \pm 44.2(5)$ \\
\hline 1 & $\operatorname{BLQ}(0)$ & $42.5 \pm 58.9(8)$ & $B L Q(0)$ & $26.8 \pm 33.5(7)$ \\
\hline 1.5 & $\mathrm{BLQ}(0)$ & $38.6 \pm 53.3(8)$ & $B L Q(0)$ & $24.4 \pm 30.8(7)$ \\
\hline 2 & $\operatorname{BLQ}(0)$ & $36.2 \pm 48.4(9)$ & $\operatorname{BLQ}(0)$ & $23.8 \pm 30.0(8)$ \\
\hline 3 & $\mathrm{BLQ}(0)$ & $30.0 \pm 36.5(9)$ & $B L Q(0)$ & $22.1 \pm 28.2(8)$ \\
\hline 4 & $B L Q(0)$ & $62.7 \pm 113(9)$ & $B L Q(0)$ & $27.9 \pm 27.5(8)$ \\
\hline 6 & $5.5 \pm 17.4(1)$ & $461 \pm 735(9)$ & $\operatorname{BLQ}(0)$ & $236 \pm 204(9)$ \\
\hline 8 & $14.6 \pm 21.2(4)$ & $1,320 \pm 1,590(10)$ & $11.0 \pm 19.1(3)$ & $975 \pm 1,240(9)$ \\
\hline 12 & $60.5 \pm 59.8(7)$ & $2,740 \pm 2,160(10)$ & $53.8 \pm 59.4(6)$ & $2,480 \pm 2,120(9)$ \\
\hline 24 & $41.1 \pm 37.7(8)$ & $3,490 \pm 2,070(10)$ & $45.6 \pm 36.9(8)$ & $3,680 \pm 2,100(9)$ \\
\hline 48 & $13.5 \pm 24.5(3)$ & $1,590 \pm 1,720(10)$ & $15.0 \pm 25.5(3)$ & $1,630 \pm 1,820(9)$ \\
\hline 72 & $2.6 \pm 8.2(1)$ & $663 \pm 902(10)$ & $2.9 \pm 8.7(1)$ & $711 \pm 943(9)$ \\
\hline
\end{tabular}

$\mathrm{BLQ}$, below limit of quantitation

a Limit of Quantitation, $20.0 \mathrm{ng} / \mathrm{mL}$

b Limit of Quantitation, $4.0 \mathrm{ng} / \mathrm{mL}$

c numbers of subjects with quantifiable concentrations are noted in parenthesis

Table 6

Summary of the mean (SEM) pharmacokinetic data for steviol and steviol glucuronide in the plasma of healthy males following consumption of stevioside

\begin{tabular}{|c|c|c|c|c|c|c|}
\hline \multirow[t]{2}{*}{ Parameter } & \multicolumn{3}{|c|}{ Plasma Steviol } & \multicolumn{3}{|c|}{ Plasma Steviol Glucuronide } \\
\hline & $E E(n=10)$ & PP1 $(n=10)$ & PP2 $(n=9)$ & $\mathrm{EE}(\mathrm{n}=10)$ & PP1 $(n=10)$ & PP2 $(n=9)$ \\
\hline $\begin{array}{l}\text { Total AUC-0.75-24h } \\
\left(\mathrm{ng}^{\star} \mathrm{h} / \mathrm{mL}\right)\end{array}$ & $783(201)$ & $783(201)$ & $736(219)$ & $\begin{array}{l}48,000 \\
(8,790)\end{array}$ & $\begin{array}{l}48,000 \\
(8,790)\end{array}$ & $\begin{array}{l}45,400 \\
(9410)\end{array}$ \\
\hline $\begin{array}{l}\text { Total AUC- } 0.75-48 \mathrm{~h} \\
\left(\mathrm{ng}^{\star} \mathrm{h} / \mathrm{mL}\right)\end{array}$ & $1,440(336)$ & $1,440(336)$ & $1,460(375)$ & $\begin{array}{l}109,000 \\
(17,900)\end{array}$ & $\begin{array}{l}109,000 \\
(17,900)\end{array}$ & $\begin{array}{l}109,000 \\
(20,000)\end{array}$ \\
\hline $\begin{array}{l}\text { Total AUC- } 0.75-72 \mathrm{~h} \\
\left(\mathrm{ng}^{\star} \mathrm{h} / \mathrm{mL}\right)\end{array}$ & $1,630(394)$ & $1,630(394)$ & $1,680(438)$ & $\begin{array}{l}136,000 \\
(25,100)\end{array}$ & $\begin{array}{l}136,000 \\
(25,100)\end{array}$ & $\begin{array}{l}137,000 \\
(28,000)\end{array}$ \\
\hline $\begin{array}{l}\text { Total AUC-0.75-inf } \\
\left(\mathrm{ng}^{\star} \mathrm{h} / \mathrm{mL}\right)\end{array}$ & $2,810(\mathrm{NA})^{\mathrm{a}}$ & $2,810(\mathrm{NA})^{\mathrm{a}}$ & $2,810(\mathrm{NA})^{\mathrm{a}}$ & $\begin{array}{l}107,000 \\
(22,300)^{\mathrm{b}}\end{array}$ & $\begin{array}{l}107,000 \\
(22,300)^{b}\end{array}$ & $\begin{array}{l}105,000 \\
(25,700)^{\mathrm{b}}\end{array}$ \\
\hline $\mathrm{C}_{\max }(\mathrm{ng} / \mathrm{mL})$ & $77.2(17.4)$ & $77.2(17.4)$ & 72.45 (18.7) & $4,470(702)$ & $4,470(702)$ & $4,400(781)$ \\
\hline$t_{\max }$ (hour) & $19.2(4.08)$ & $19.2(4.08)$ & $20.0(4.47)$ & $21.6(3.49)$ & $21.6(3.49)$ & $22.7(3.71)$ \\
\hline$t_{1} / 2$ (hour) & $15.4(\mathrm{NA})^{\mathrm{a}}$ & $15.4(\mathrm{NA})^{\mathrm{a}}$ & $15.4(\mathrm{NA})^{\mathrm{a}}$ & $18.6(4.03)^{\mathrm{b}}$ & $18.6(4.03)^{b}$ & $18.8(4.64)^{b}$ \\
\hline
\end{tabular}

${ }^{a} n=1$; SEM was not estimable. For plasma steviol, total $A \cup C-0.75-\infty$ and terminal half-life $(\mathrm{t} / 2)$ were estimable for one subject only (Subject \#007)

${ }^{b} \mathrm{n}=8$ for EE and PP1; $\mathrm{n}=7$ for PP2. For plasma steviol glucuronide, total $\mathrm{AUC}_{-0.75-\infty}$ was inestimable for 2 subjects (Subject \#010 and \#014) 
Table 7

Ratios of Plasma steviol glucuronide to steviol for $A U C_{0-24 h}, A U C_{0-48 h}, A U C_{0-72 h}$, and $C_{\max }{ }^{a}$

\begin{tabular}{llll}
\hline Parameters & \multicolumn{2}{l}{ Ratio of steviol glucuronide to steviol } \\
& EE $(\mathrm{n}=9)$ & PP1 $(\mathrm{n}=9)$ & PP2 $(\mathrm{n}=8)$ \\
\hline Total AUC-0.75-24h & $86.8 \pm 17.6$ & $86.8 \pm 17.6$ & $90.3 \pm 19.5$ \\
Total AUC-0.75-48h & $89.9 \pm 12.5$ & $89.9 \pm 12.5$ & $90.1 \pm 14.2$ \\
Total AUC-0.75-72h & $99.7 \pm 14.7$ & $99.7 \pm 14.7$ & $99.4 \pm 16.7$ \\
C $_{\max }$ & $71.7 \pm 10.3$ & $71.7 \pm 10.3$ & $75.4 \pm 10.9$ \\
\hline
\end{tabular}

a Values are Mean \pm SEM

b One subject (Subject \#013) had plasma steviol levels below the lower limit of quantification $(20 \mathrm{ng} / \mathrm{mL})$ at all time points. For this subject, the ratios of plasma steviol glucuronide to plasma steviol for $A U C$ and $C_{\max }$ were not estimable. 
Figure 1. Steviol-based backbone structure of steviol glycosides

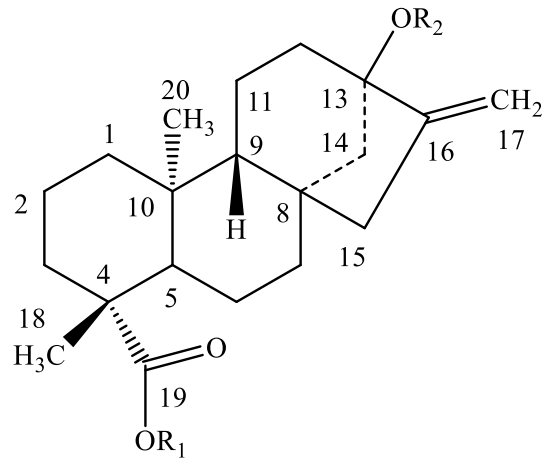


Figure 2. Mean $( \pm S D$ ) concentrations* of steviol and steviol glucuronide in plasma of male and female rats following oral administration of stevioside at $40 \mathrm{mg} / \mathrm{kg}$

* See Table 1 for the number of individual animals with quantifiable concentrations.
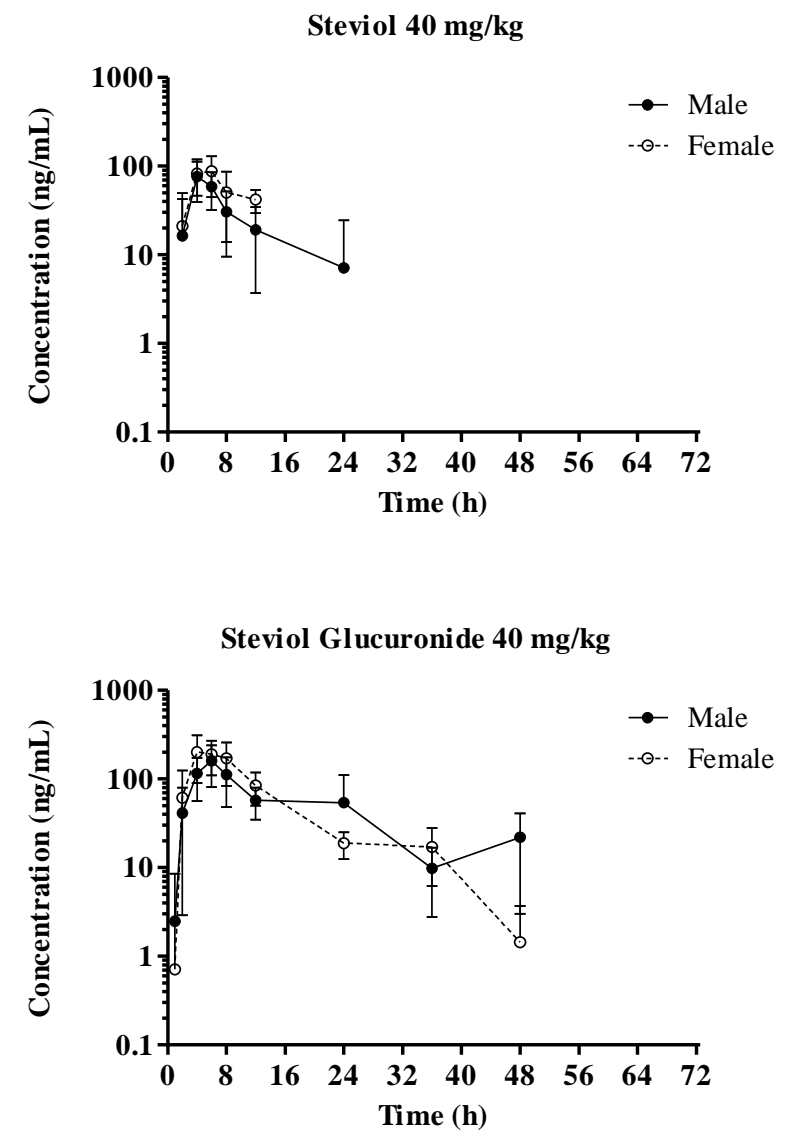
Figure 3. Mean $( \pm S D$ ) concentrations* of steviol and steviol glucuronide in plasma of male and female rats following oral administration of stevioside at $1,000 \mathrm{mg} / \mathrm{kg}$

*See Table 2 for the number of individual animals with quantifiable concentrations.
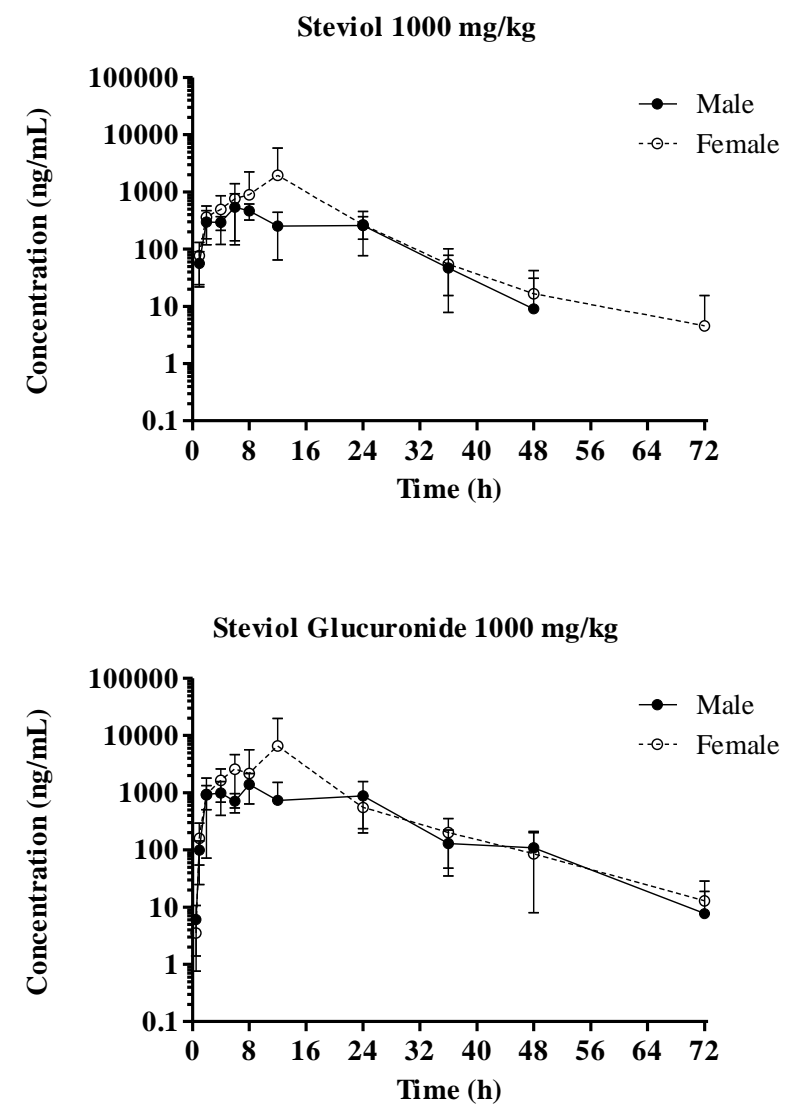
Figure 4. Area under the plasma concentration-time curves $\left(A \cup C_{\text {last }}\right)$ and peak plasma concentrations $\left(\mathrm{C}_{\max }\right)$ for steviol and steviol glucuronide following oral administration of stevioside at 40 or $1,000 \mathrm{mg} / \mathrm{kg}$ to male and female rats
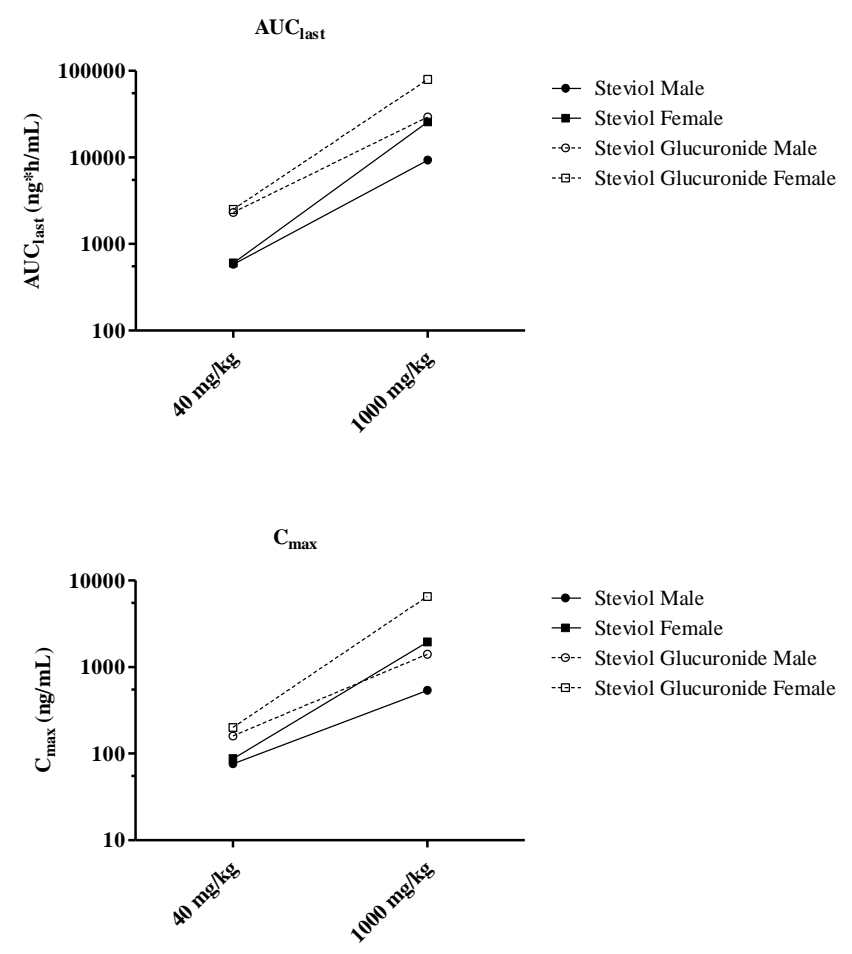
Figure 5. Dose-normalized area under the plasma concentration-time curves (AUClast) and peak plasma concentrations $\left(\mathrm{C}_{\max }\right)$ for steviol and steviol glucuronide following oral administration of stevioside at 40 or $1,000 \mathrm{mg} / \mathrm{kg}$ to male and female rats

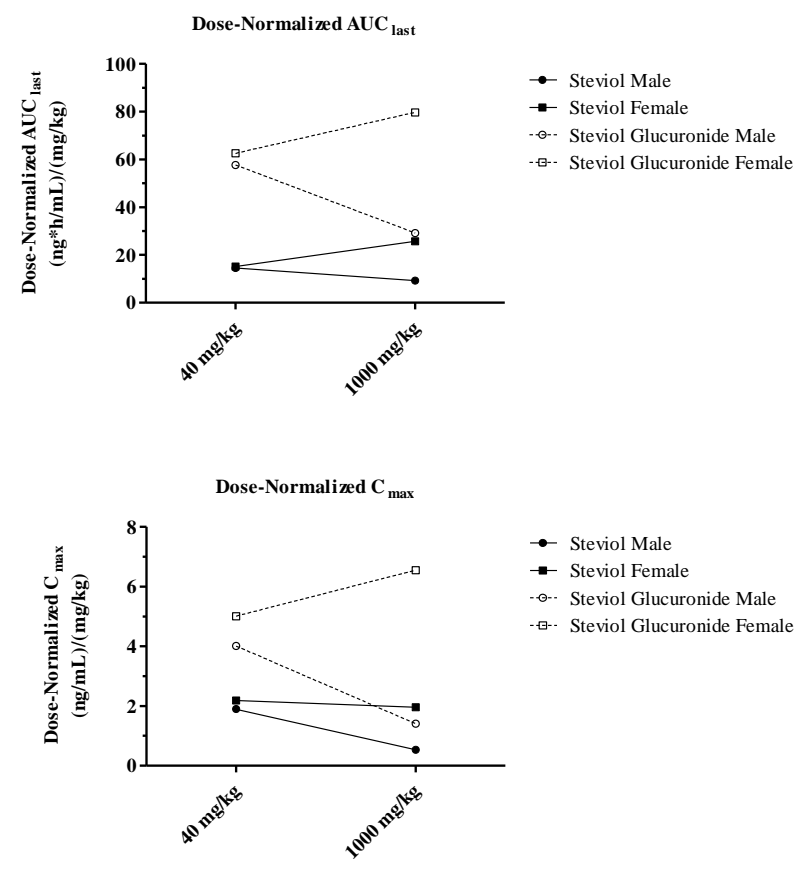


Figure 6. Mean $( \pm S D)$ concentrations* of steviol and steviol glucuronide in plasma of human male subjects following oral administration of stevioside at $40 \mathrm{mg} / \mathrm{kg}$

* See Table 5 for the number of individual subjects with quantifiable concentrations.
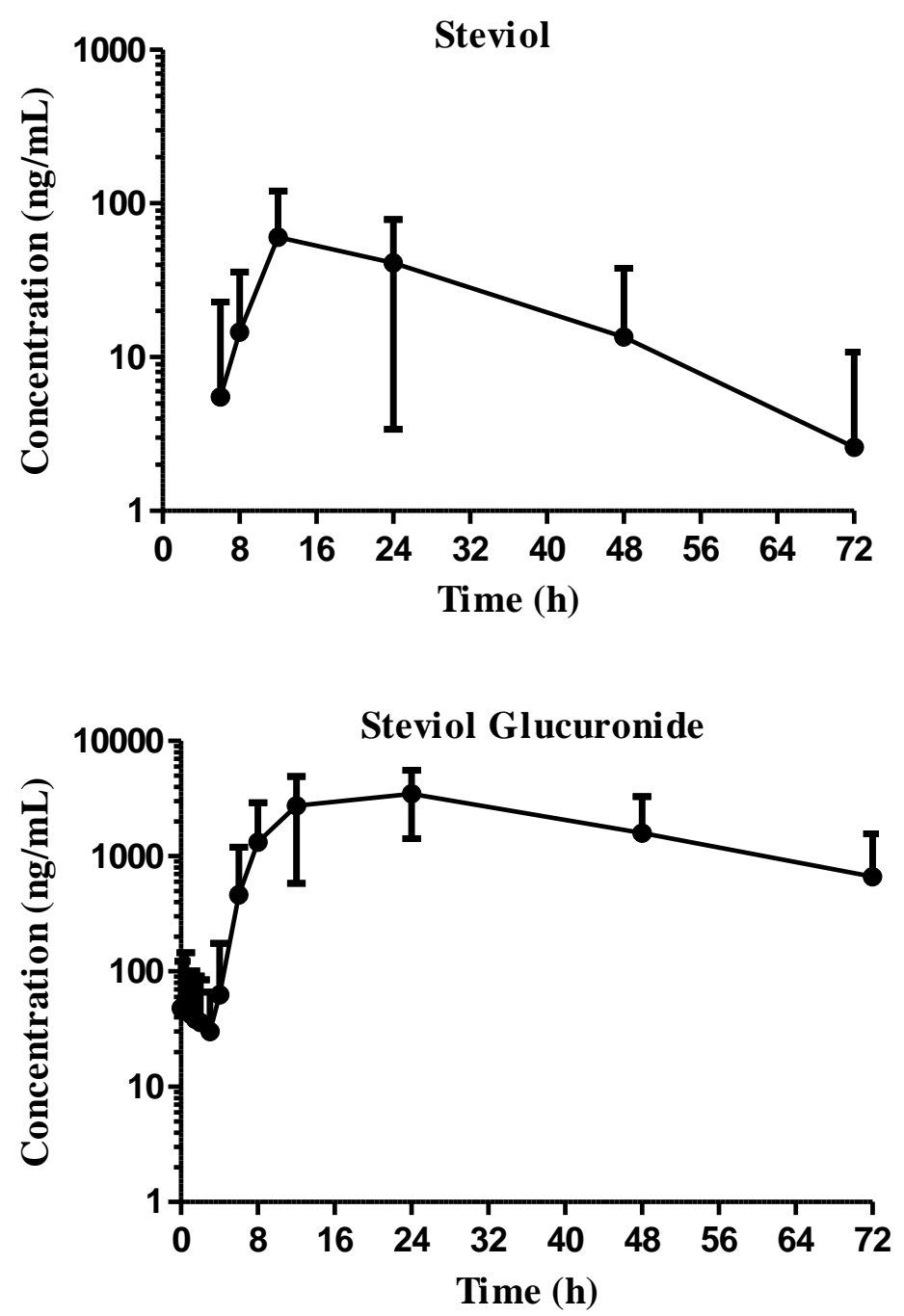